\title{
Thermal reactions involving solids: a personal view of selected features of decompositions, thermal analysis and heterogeneous catalysis
}

\author{
Andrew K. Galwey ${ }^{1}$ \\ Received: 8 July 2019 / Accepted: 15 February 2020 / Published online: 24 March 2020 \\ (c) The Author(s) 2020
}

\begin{abstract}
Convinced that some recent trends in the literature concerned with reactions involving solids have been unproductive, even discouraging interest in the subject, this reviewer analyses the reasons and charts a way forward. In particular, two topics are discussed: thermal analysis and activation energy. Thermal analysis, automated collection and interpretation of kinetic data for solid(?)-state decompositions, resulted in huge numbers of publications between late 1970s and 2010. Measurements were frequently minimalistic (few, often no, confirmatory tests complemented rate data). Kinetic data interpretations were based on the Arrhenius activation model, inapplicable to these assumed, usually unconfirmed, solid-state(?) reactions. Energy distributions within crystalline reactants differ from those of 'free-flying' gaseous reactants, and thus, mechanistic proposals are entirely speculative. Such studies yielded little more than the reaction temperature: no meaningful insights into reaction chemistry, controls, mechanisms. Despite my several highly critical articles, these inconsequential studies continued. Overall, this now sidelined topic impacted adversely on solid-state chemistry, activation energy, $E$. Concurrently with the above studies, L'vov published a theoretical explanation for the magnitude of $E$ : the Congruent Dissociative Volatilisation (CDV), thermochemical approach. This was also ignored by the 'Thermoanalytical Community', possibly because it assumes an initial volatilisation step: it appears that many solid-state scientists are prejudiced against mechanisms involving a phase change. The value of this novel theory (CDV) in identifying controls and mechanisms of solid-state reactions is discussed here. This review is positive: an interesting branch of main-stream chemistry remains open for exploration, expansion, explanation and exploitation!
\end{abstract}

Keywords Solid decompositions with melting $\cdot$ Solid decomposition kinetics $\cdot$ Solid decomposition thermodynamics

\section{Introduction}

Prior to the 1980 s, the thermal reactions of solids formed a thriving branch of main-stream chemistry. Behaviours characteristic of solids differ from those of other reaction types, e.g. in liquids and gases, but generally contributes by advancing chemical science overall. A brief overview of these researches is given below, to provide context for the present, much more specific, review. This

Andrew K. Galwey

aandk.galwey@talktalk.net

1 School of Chemistry and Chemical Engineering, The Queen's University of Belfast, University Road, Belfast BT7 1NN, Northern Ireland article focuses primarily on two selected features of thermal reactions involving solids that the author believes merit this retrospective review, from which lessons may be learned. The first is thermal analysis which, for a time, attracted considerable interest, yielding numerous publications. The second is activation energy which has usually, particularly when interpreting thermoanalytical data for solid reactants, been regarded as synonymous with the Arrhenius model, developed to be applicable to reactions of gases. 


\section{Thermal Analysis: Introduction}

During the late 1970s and early 1980s, versatile, automated equipment was developed capable of recording and analysing kinetic data, rapidly becoming widely available. Such apparatus enabled accurate measurements to be obtained and stored, of mass losses (thermogravimetry) or heat evolution/absorption (differential scanning calorimetry) during thermal reactions of (at least initially) solid reactants. Reaction rates could be measured either at a constant temperature (isothermal) or for programmed temperature regimes (non-isothermal, often for a constant rate of temperature rise). These rate measurements could then be kinetically analysed and interpreted, within the same equipment, to provide insights into reaction controls and mechanisms $[1,2]$.

Obvious attractions of this method for studying the thermal decompositions of solids are that results can be obtained rapidly, efficiently and with relatively little effort by the researcher, other than identifying and preparing (or buying) reactants selected as being worthy of study. This explains the surge of interest, starting and continuing after the late 1970s, which yielded a huge collection of articles reporting kinetic studies for many, many diverse solid(?) reactants. Several journals were established, specialising in publishing these and related topics, including Journal of Thermal Analysis and Calorimetry and Thermochimica Acta. Indeed, over time, Thermoanalytical Studies tended to replace, at least in part, the former, wider, interests in thermal chemistry of solids. This contributed, at least in part, to the publication of fewer studies of solid-state reactions in main-stream chemical journals. Instead, Thermoanalytical Studies were to be found, virtually exclusively, in its specialist literature. This 'sidelining' specialisation is now recognisable as a 'cul-de-sac', leading nowhere and separating solid-state thermal reactions from 'main-stream chemistry'. One motivation for this article is to reconnect solid-state studies with the wider chemical literature.

This review records significant features of this 'rise and fall' of Thermoanalytical Studies, which has contributed to some overall reduction in interest in solid-state chemistry. Reasons for this 'fall', discussed with citations below, include limitations inherent in the experimental approach, together with fundamental shortcomings in the theory used to interpret the usually inadequate, minimalistic observations. The several decades-long focus on Thermoanalytical Studies has yielded remarkably few (if any) insights into the thermal chemistry of solids, while partially replacing the former, 'more chemical' studies. Several articles by this author have pointed out these shortcomings in the relevant literature, but, as is emphasised below, these have been widely and systematically ignored. Nevertheless, this formerly 'fashionable' topic now seems to have effectively run its course.

Throughout this article, the term 'Thermoanalytical Studies', TAS, is used to embrace comprehensively the literature of this specific topic, during its most active phase from its rise in the late 1970s to its decline in the late 2010s.

\section{Activation energy}

Dominant within the literature concerned with reactions of solids is the unstated and unjustified assumption that the 'activation energy', $E$ (conventionally calculated from the linear variation of $\ln k$ with $T^{-1}$ ), has the same mechanistic significance as that originally proposed by Arrhenius for reactions between gases. Based on this model, data have frequently been interpreted to propose a rate-limiting step and/or other mechanistic features. However, application of this model to reactions involving solids overlooks the fact that energy distributions of the constituents of crystals are much more restricted than between 'free-flying' constituents of gaseous reactants. A different theory is required.

Such a theory was developed by L'vov, through an alltoo-rare cross-fertilisation of ideas between quite different branches of chemistry. L'vov, working on the evaporation of analytes for spectrochemical analysis, investigated the possibility that the controlling step in breakdown of a solid reactant could be the volatilisation of the precursors to chemical change. Such a step, requiring a phase change, was (evidently) anathema to solid-state scientists, apparently never having previously even been considered and is still far from being generally accepted. However, L'vov has measured quantitatively the volatility of many solids and shown conclusively that these small vapour pressures are sufficient to account for the thermal decomposition rates of many representative (solid) reactants. This theory, the L'vov Congruent Dissociative Volatilisation (CDV), thermochemical approach, is outlined below and explained, with examples, in much greater detail in [3]. This novel theory, advocated below, offers scope future research in this interesting branch of chemical science which now appears as a topic ripe for worthwhile and long-overdue reinvigoration. This review in intended to provide some historical background to this current opportunity.

\section{Early history and theory of solid-state reactions, before the 1980s}

In 1955, a multi-authored, authoritative and comprehensive review of this subject was published: 'Chemistry of the Solid State', edited by Garner WE [4]. This valuable seminal work provides a contemporary overview of the state of knowledge of various reaction types involving solid 
reactants. Specifically, this editor discusses [5] the nucleation and growth, $n+g$ model, of solid-state decompositions (including dehydrations) to which he made fundamental, significant contributions. Photomicrographs of nuclei are included in [5].

The $n+g$ reaction model identifies chemical reactions of many solids as being initiated at relatively few sites at the surfaces of reactant crystals. Each such initiation yields a nucleus, preferentially formed at points of surface damage or at crystallographic defects, enabling its transformation here into an embedded particle/crystallite of product. After the (initially small, less-stable) germ nucleus has grown and stabilised, it has formed active reactant/product interfaces, wherein reaction occurs preferentially. Such promotion of reaction here, autocatalysis, has been ascribed to strain and/ or catalysis at or within the intercrystal, reactant/product contact interface.

Overall kinetic behaviour is quantitatively controlled topologically by the changing total geometric area of all participating interfaces, advancing at the same constant rate into the remaining reactant. Reaction at these, initially increasing, interface contact areas results overall in an early stage of accelerating rate process. Later, growth nuclei on each particle impinge, reducing the total area of active interface contacts, causing a deceleration of overall reaction rate. Many $n+g$ reactions, therefore, typically exhibit [6] characteristic sigmoid-shaped $\alpha-t$ (yield-time) curves ( $\alpha$-fractional reaction and $t$-time).

Thus, the kinetic characteristics of $n+g$ type reactions are controlled by geometric factors, representing the changes in the total area of participating interfaces, which varies as these form, advance and later coalesce. (This characteristic mechanistic behaviour differs fundamentally from homogeneous rate processes, in gas or liquid phase, wherein reaction rates are determined by changes of reactant concentrations, or other mechanisms, such as chain reactions). In [4], Jacobs and Tompkins [6] used the various known features of $n+g$ models to formulate systematically a range of geometry-based kinetic, rate $(\alpha-t)$ expressions. Nucleation can be instantaneous, linear or exponential with time: aspects of nucleation processes are also discussed in [6]. The rate of interface advance with time is generally constant, but advance can take place in 1, 2 or 3 dimensions. The several possible combinations of nucleation with growth processes lead to a set of rate equations of the general form: $f(\alpha)=k t$ (where $\alpha$ is the fractional reaction, zero at time $t=0.00$ and 1.00 on completion). In addition, sizes and shapes reactant crystals may be taken into account. Later reviews, updating this topic, include [7, 8]: these equations are discussed in greater detail in [8], with those most frequently used listed in Table 3.3, pp. 103-106.

Three distinctive patterns of $\alpha-t$ curve shapes merit mention: (1) sigmoid shaped, see above, (2) deceleratory throughout, following initial rapid nucleation across all surfaces: contracting volume (3D) or area (2D) geometries, and (3) strongly deceleratory behaviour of gas + solid type reactions, controlled by a diffusion process with contracting geometry across a layer of barrier product. Initial reactant crushing can raise decomposition rates by increasing the surface areas on which reaction is initiated, further enhanced by abrading, often effectively nucleating all surfaces initially, at $t=0$.

For isothermal, solid-state rate data, the rate expression, $f(\alpha)=k t$, giving the 'best fit' to a set of kinetic measurements, may be found by graphical and/or statistical analysis. This fit is then interpreted as the reaction topology, often termed 'reaction mechanism'. Rate constants, $k$ (units $t^{-1}$ ) can be obtained as slopes of linear plots of $f(\alpha)$ versus $t$ and/or statistical methods. Plots of $\ln k$ versus $T^{-1}(T / \mathrm{K}$, temperature for each isothermal reaction of the set) are generally linear, although this is rarely confirmed. From these, the Arrhenius parameters, $A$ and $E$, ('frequency factor' and 'activation energy', respectively), are almost invariably calculated. (The 'Arrhenius model' is, however, inapplicable to reactions involving solids, discussed below.) Kinetic analyses of non-isothermal rate data are not reviewed here (see [8], Chap. 5). Although the correct unit for $k$ is (time) $)^{-1}$, data analyses using power laws sometimes (incorrectly) start with $\alpha=k t^{n}$ giving ' $E$ values' in error by a multiple of $n$, i.e. $x n$.

Kinetic analyses of rate data measured in Thermoanalytical Studies, TAS, have almost invariably been directed towards identifying which equation provides the 'best fit' from a set of (usually) 20-25 possibilities [8] (sets selected by different authors vary slightly). These sets of kinetic expressions include: (1) the several geometric/topological expressions based on interface advance models, $f(\alpha)=k t$, and (2) those characteristic of homogeneous reactions, reaction orders, controlled by reactant concentrations. Despite being counter intuitive, this obviously non-uniform set of equations (i.e. heterogeneous and homogeneous) has received wide acceptance for use in this type of kinetic analyses. Measured kinetic data, for breakdown of each target reactant, is then competitively compared with the 'fits' for every equation of the set. Such analyses can be automated in the apparatus computer and 'fits' compared statistically or graphically. The rate equation found to provide 'best fit' is then usually reported as the 'reaction mechanism'.

Two aspects of this literature merit (adverse) comments. First, the range of equations comparatively tested usually derive from quite different mechanistic rate controls: geometric, concentration, product barrier layer. Incompatible mechanistic explanations are treated equally. Moreover, most studies include no complementary observations, such as microscopic studies to detect melting or $n+g$, etc., thereby confirming that a kinetically deduced reaction 'mechanism' is compatible with the 'best-fit' rate equation. In many reports, it appears to have 
been implicitly assumed that the decomposition of an (initially cold!) solid reactant occurred in the solid state, with the possibility of melting, eutectic or intermediate formation being routinely ignored. Another feature worth recording, but usually omitted, is the $\alpha$ range across which a 'fit' applies. This can be significant because different rate equations may provide 'best fits' across different $\alpha$ intervals.

Second, although early solid-state thermal reaction studies [4-8] recognised the (then novel) role of geometric controls in reaction kinetics, unfortunately the equally relevant, complementary problem of applying the similarly inappropriate, homogeneous Arrhenius model to reactions involving solids remained unaddressed. Consequently, an (essentially gas-phase) reaction model still continued in general use for the kinetic analysis of solid-state reactions. This is important because the broad energy distributions, characteristic of 'freeflying' reactant precursors, do not apply to the less mobile reactant precursors restrained at, on or in a solid surface or interface. Energy distributions for surface-bonded reaction precursors, including active, possibly mobile, participants in heterogeneous catalytic reactions, are not expressed by the Boltzmann equation. Consequently, the persistent use of the Arrhenius model, $\ln A$ and $E$, underlies and contributes to some of the problems confronted in this review. Its continued use has effectively prevented meaningful insights into solidstate reaction chemistry, controls and mechanisms.

In addition to the above reviewers, notably Garner, Tompkins and Jacobs, mentioned first here to underpin the subject theory, definitions, etc., outlined above, many other researchers have contributed to the advance of solid-state chemistry. The author has no intention of attempting to appraise the relative values of the large and small inputs by these uncounted individual contributors. Their offerings certainly cannot be meaningfully compared. However, Boldyrev's many and significant inputs into developing our understanding of the thermal chemistry must be mentioned [9-11]. Examples include the decompositions of silver oxalate [12] and ammonium perchlorate [13], both of which later became reactants of choice for studies by other researchers. During his productive years, he led the Group for the Reactivity of Solids, Novosibirsk, Russia, between 1978 and 2013, before being succeeded by his daughter, Elena V. Boldyreva from 2013 to 2017. The output from this group still continues, including the very recent publications [14-17].

\section{The rise of 'thermal analysis', later (at least partially) replacing chemical studies of solid-state thermal decompositions}

By the early 1980s, computer developments had advanced sufficiently for laboratory equipment to be automated. Former manually operated experimental techniques were now replaced by equipment capable of measuring and recording $[1,2]$ reactant mass losses (thermogravimetry, TG) or heat evolved/absorbed (differential scanning calorimetry, DSC) at specified intervals during isothermal or non-isothermal reaction regimes. From the data measured, collected and stored by such apparatus, fractional reaction, $\alpha$, values could be calculated for specified reaction times, $t$, together with recorded temperatures, $T$.

Each reaction rate data set $(\alpha, t, T)$ stored could then be analysed to test and compare the 'fits' of each $\alpha-t$ data set to every one of the appropriate group of kinetic rate expressions [6-8]. Such 'appropriate groups', selected by each researcher, usually included most of those in the sets of (20-25) diverse rate equations mentioned above. Different sets of kinetic expressions must be used for isothermal and for non-isothermal data: the monograph [1] can be recommended as an authoritative and general overview of this subject. The 'best-fit' kinetic expression, preferred by the researcher(s), is then usually reported as the reactant decomposition 'mechanism', frequently also with the calculated values of (Arrhenius) activation parameters, $\ln A$ and $E$. Some researchers further interpret this $E$ magnitude as evidence of a particular 'rate-limiting step' in reactant breakdown.

Equipment capable of such highly automated kinetic studies was marketed by manufacturers, soon becoming widely available. These sophisticated apparatuses found many applications in industry, e.g. for product quality control and to estimate drug deterioration rates during storage in hot climates, etc. However, the present review focuses on the significant impact that Thermoanalytical Studies, TAS, had, using such equipment, on chemical aspects, rate controls and reaction mechanisms, of solid-state thermal decompositions from the late 1970s to the mid-2010s and the as-yet (apparently) incompletely recognised (or ignored!) legacies. The potential of this automated approach to chemical kinetic investigations was rapidly appreciated and exploited by many researchers so that publications reporting thermal decompositions of (initially solid) reactants rapidly proliferated. An unknown, but overall huge, number of reports of these types of studies appeared in its dedicated literature, including Journal of Thermal Analysis and Calorimetry, Thermochimica Acta, etc.

The generalisations made below about this extensive literature (including probably thousands of articles) are intended to emphasise features that occur sufficiently frequently to be regarded as typical of the 'average' report. The author fully accepts that there are exceptions of different and diverse types: the accumulated contents of the available reports cannot be meaningfully 'averaged'. The important consequence is that the shortcomings evident in a majority of such publications inevitably casts doubt on, thereby ultimately devaluing all the scientific, chemical significance of the 'kinetic 
conclusions and interpretations' described therein. Indeed, automation of data interpretation itself has its shortcomings. During a long period of refereeing many such papers, this reviewer was often left with the strong impression that many authors of such articles did not adequately understand the theory used, including possible limitations, weaknesses, inaccuracies, etc., of the programmes to which their observations were delegated for 'analysis'. 'Black-Box' Chemistry! The ultimate appearance, from the machine, of a printed outcome for reactant breakdown: 'reaction mechanism' (i.e. rate equation), $\ln A$ and $E$, carries its own (spurious) 'Authority'. 'Raw' data always benefit from critical appraisal by the experienced researchers: such insights remain, as yet, outside the computer's abilities.

The wide-ranging generalisations expressed below are not all directly supported by specific citations in this review. Access to the very many relevant references are, however, readily available, cited in the eleven articles, discussed in detail and critically appraised here [18-28]. Together, these articles present the types of criticisms that are the foundations of the present systematic, critical survey. This approach is now considered justified because all such adverse comments about shortcomings, limitations, inconsistencies and imprecise terminology that permeate the relevant literature have been ignored, evidently wilfully, throughout the subsequent Thermoanalytical Studies, TAS, literature. L'vov has expressed the same pessimistic conclusion, e.g. [29, 30]. His thermochemical $(C D V)$ approach to rate data interpretation for solid-state thermal reactions [3] (discussed below) has similarly failed to attract the attention and interest it richly deserves.

This disregarding of the challenging literature is highly unscientific and, therefore, deeply disturbing. Throughout science, experimental observations are accepted as the ultimate 'Court of Appeal': the concurrent availability, and use, of rival theories represents a state of 'unstable equilibrium'. The scientific communities concerned are morally obliged to test comparatively all alternatives to destruction and identify definitively the (single) theory best representing the observations for use thereafter. This may require its modification and lead on to later developments, by up-grading or replacement. Thus science advances. However, this is not occurring and, indeed, has been positively resisted, by authors contributing to the Thermoanalytical Studies, TAS, literature. In many/ most publications, 'Introductions' frequently fail to set the article content in its context and very many 'Discussions' fail to mention and discuss possible weaknesses and shortcomings. Reports tend to be inward looking, each communicating less than its potential. An unacceptable situation!

This feature is an illuminating example of the famous quotation, attributed to the physicist Max Planck [31, 32]: 'Science advances one funeral at a time'. This memorably expresses the truism that replacement of an outdated, failing scientific theory can be slow, delayed until after the departure (funerals) of the generation resolutely maintaining its application. So it was with phlogiston, the theory overturned only slowly [33] during the 1780s. The present review, together with [18-30], emphasises the extended reluctance, by the active sustainers of older concepts, to replace their outdated, inappropriate theory by ignoring both its criticisms and a proposed replacement theory (CDV, discussed below). Prolonged stagnation $[20,27]$ has followed; so that now the area is more realistically described as moribund, by failing to attract the interest of researchers. Judging by the recent falls in the numbers of Thermoanalytical Studies, TAS, appearing, it seems that this topic is reaching a natural termination. The optimistic feature is that the subject it partially 'replaced' is now ripe for continued exploitation by research into the chemistries of thermal reactions of initially solid reactants. Representative chemistry-based studies of thermal decompositions of some solid (at least initially) reactants are mentioned below.

The publication of 'Decomposition Reactions of Solids: An Experiment in Reviewing' [34] provided a comprehensive survey of all the articles, concerned with solid-state thermal decompositions, that were published in the calendar year 1981. In all, 368 articles were found (1/day!) and, with an average of 3.48 reactants in each article, this corresponds to about 1280 reactants overall, though some feature more than once. The content of this set was analysed, showing the publication source, the types of compounds studied, the methods used, results obtained, etc. This unusual literature survey fortuitously occurred towards the end of the earlier studies of the chemistry of solid-state thermal reactions and during the onset of its partial replacement by the Thermoanalytical Studies, TAS. It [34] reveals the considerable investment and activity in the field at that time, contrasting with the subsequent diminishing interest, decline or even demise, of the 'TAS era'.

\section{Shortcomings and limitations of thermoanalytical systems, TAS, theory as described in Refs. [18-30]}

Features of the theoretical shortcomings in thermal analysis publications are critically reviewed here as a cautionary guide addressed to readers and literature-searchers browsing previous investigations to identify promising, worthwhile research targets.

A central, pervasive weakness of Thermoanalytical Studies, TAS, in many/most papers appearing after the late 1970s was the frequently minimalistic experimental input, using the fewest possible rate data observations (or less!) [18-30] unsupported by complementary observations. (Briefly, the possibility of using a single non-isothermal experiment was considered: a single kinetic 'run' per reactant!). Moreover, theory, term definitions and underlying assumptions 
have similarly remained unexamined and rarely critically appraised or even discussed [28]. Mechanistic conclusions, in (probably) a majority of such articles, remained unsupported by any microscopic or analytical confirmatory observations (qualitative or quantitative) $[18,28]$. Specifically, to obtain meaningful mechanistic conclusions, the phase in which the reaction occurs must be known. Just because the original reactant, placed in a (cold) reaction vessel, is a solid, this does not mean that it does not melt (the most common result of heating a solid!) before onset of the target reaction. The possibility of fusion was rarely tested or even mentioned. Indeed, it seems, to this 'sceptical chemist', that often the report of an $E$ value enabled a publication to be 'scored'.

To interpret thermal reaction mechanisms fully, kinetic studies require a range of appropriate complementary investigations. These may include microscopy and analytical identifications of all intermediates formed, together with measurements of their amounts present across a range of reactant samples, previously partially decomposed to known $a$ values. Such reaction intermediate(s) may melt, or form a molten eutectic within which reactions may occur, which can, and some do, exhibit initially acceleratory behaviour, also a characteristic of $n+g$ reactions. These alternative distinctive rate behaviours are not always or easily distinguished by the kinetic analysis of rate data. Finally, though rarely, a reactant, intermediate or product may volatilise, e.g. copper(I) formate (see below).

\section{The Arrhenius equation and calculations of $\ln A$ and $E$ in Thermoanalytical Studies, TAS}

According to the Arrhenius homogeneous reaction model, product formation results from collisions 'more energetic' than the minimum, $E$, required to enable bond redistributions to occur within/between 'dynamic interactions' of reactant molecules. Thus, from the temperature-dependent changes in energy distribution amongst the reactant molecules, the magnitude of $E$ can be calculated using the Arrhenius equation. (Extensively discussed in widely available in text books on physical chemistry, etc.) The feature relevant here is that the energy distribution spreads within homogeneous reactants are broader than those within/on solids, where the thermal vibrations are constrained between more closely spaced and less mobile (crystal) constituents and adsorbed species. This topic was discussed further by Garn [35-37]. Although rarely confirmed, plots of $\ln k$ (time $)^{-1}$ versus $(T / K)^{-1}$ have been shown to be linear for many representative solid-state reactions. However, the Arrhenius model is not applicable to such reactions and (speculative) mechanistic interpretations based on calculated $E$ and $\ln A$ magnitudes can only be empirical [20], lacking chemical significance. Nevertheless, these have a limited value by enabling rate constants to be reliably estimated for temperature intervals beyond those measured, e.g. in estimating long-term stabilities of drugs, medicines [38, 39], for quality controls in manufacturing industry, etc. A related solid-state issue, drug solubilities [40], may be appropriately mentioned here.

In 2000, a set of papers [41] reported the results of an interesting comparative study in which researchers active in the field were invited to undertake kinetic analyses of the several sets of rate data provided. These data sets included both experimentally measured yield-time values, directly obtained from kinetic studies of $\mathrm{NH}_{4} \mathrm{ClO}_{4}$ and of $\mathrm{CaCO}_{3}$ decompositions, together with some computed kinetic data sets (i.e. not measured in a laboratory). Each participant was free to choose their own preferred interpretive method(s). In all, 19 authors contributed to the main article: 'Computational aspects of kinetic analysis. Part A. The ICTAC kinetic project—data, methods and results'. Some of these authors also contributed to the supplements that followed, Parts B-E [41].

A detailed appraisal of the many 'conclusions' (some showing inconsistencies) presented in Parts A-E of [41] is inappropriate here. The only positive outcome mentioned in the Abstract of Part A is: 'Reasonably consistent results were obtained for isothermal and non-isothermal data'. The reader might find it illuminating to peruse the contents of these reports and decide for him/herself whether (or not) the various calculated magnitudes of $\ln A, E$ reported achieved acceptable agreement levels. We believe that a disinterested observer could reasonably expect that results, calculated from identical data sets by the most experienced researchers in the field, would show very close agreement. We think it is fair to say this was not achieved. We express surprise, therefore, that this study was apparently not followed by detailed inquests into reasons why and how these appreciable differences arose. Moreover, steps should be taken to ensure, as far as is practicable, that, in future, all data interpretations yield meaningful, reliably calculated Arrhenius parameters. Certainly, the ethos of the subject has not been improved by the questionable level of agreement achieved in this revealing methodological enquiry.

The level of scatter of $\ln A, E$ magnitudes revealed here [41], if general, could be a significant factor in the lack of order within the Thermoanalytical Studies, TAS, literature (discussed below). Although this study, involving many of its most preeminent researchers, shows significant inconsistencies in the data calculated, no attempt appears to have been made to correct these appreciable (at best) shortcomings: excuses suffice instead! (Although aware of the open invitation, this author did not participate, anticipating that the initiative would achieve little of value. In retrospect, I believe my decision was realistic!).

Diverse methods of kinetic data analyses, particularly for non-isothermal studies $[1,2,7,8]$, have been used by 
researchers, some being labelled by the name(s) of their proposers: e.g.: Flynn-Wall-Ozawa, Friedman, Sestak-Berggren, etc. However, such reports do not always adequately explain or justify the reasons why a particular data analysis expression/method was selected or preferred. We know of no systematic, comprehensive and comparative review of the strengths and weaknesses of the many available alternative methods of non-isothermal kinetic analyses. Yet another serious literature omission.

\section{Influence of ambient gas pressures on reaction rates, $\operatorname{In} A$ and $E$ values for solid-state decompositions}

Reaction rates, $\mathrm{d} \alpha / \mathrm{d} t, \ln A, E$ values calculated in different decomposition studies of the same reactant often vary significantly, though usually this trend has evidently neither been noticed nor discussed by thermochemists. Such trends may alternatively arise through erroneous calculation methods [41] (e.g. incorrect definition units: $k(t)^{-\mathrm{n}}$ or $k(t)^{-1}$ ) and/ or the influences of any gases present. L'vov has confirmed the latter trend: showing that values of $(\mathrm{d} \alpha / \mathrm{d} t), \ln A$ and $E$ for thermal reactions of many solids vary systematically with the pressures of gaseous product(s) present within the reaction zone [3, 29, 30, 42, 43]. This is evidence for the participation of a volatilisation process in rate control and is inconsistent with the Arrhenius model wherein an activation step, $E$, is assumed to control an intracrystalline or a surface processes. Because solid-state reactions are not expected to be influenced by gases present, they are routinely ignored in Thermoanalytical Studies, TAS. This feature of solid-state thermal reactions does, however, provide important support for the (novel, distinctive) thermochemical (CDV) approach to rate data interpretation [3] (discussed below).

\section{Significance of the term 'reaction mechanism'}

Throughout the Thermoanalytical Studies, TAS, literature, the term 'reaction mechanism' is frequently and implicitly regarded as the rate equation providing the 'best fit' to $\alpha-t(-T)$ data sets measured for the selected (solid?) reactant. The significance of this concept is, however, rarely explicitly defined and/or discussed: consequently, its meaning has become somewhat elastic. For homogeneous rate processes, from whence the term was imported, it embraces everything that can be learned about a target reaction, including characterisation of all reactants (and, if appropriate, structure, purity, etc.) and products, also, during reaction, any involvement of fusion, intermediates, catalysts and all other influences, e.g. radiation. In addition, there may be consideration of a 'Transition State': which bonds are reorganised and how, electronic and stereochemical reconfigurations, the energetics of all participating steps, etc. In short, 'mechanism' includes every accessible detail contributing to a comprehensive portrayal of the reaction chemistry.

In Thermoanalytical Studies, TAS, this confusing use of 'reaction mechanism' serves to conceal the fact that such kinetics-only investigations yield no insights into reaction chemistry, e.g. precursors, strain, etc., at the advancing interfaces. The use of this term is both pretentious and presumptuous. An adequate 'fit' of measured rate data to a topologically derived rate equation can give evidence about the probable geometric pattern of interface development during an $n+g$ reaction in a solid or any other kinetic equation within the set compared. Moreover, in the literature such deductions are but rarely supported by confirmatory observations. For suitable reactants, visual inspections of partially reacted crystals can be capable of more reliable and more rapid characterisation of a $n+g$ model of reaction geometry. Microscopy is not used, presumably due to unfamiliarity, being rarely helpful throughout most other branches of chemistry.

Measured magnitude(s) of $E$ are sometimes 'interpreted' to identify the bond ruptured in an entirely speculative 'rate-limiting step' which (presumably) takes place on, at or below the surface/interface crystal layer(s) of the reactant. Virtually nothing is known about precursors to the interface steps participating in solid-state thermal reactions, generally inaccessible to investigation. Throughout Thermoanalytical Studies, TAS, $E$ values have not yet been related to any parameter characteristic of reactants: structures, compositions, thermodynamic quantities, etc. Reasons include the absence of reviews across this subject area and the superficiality of Introductions and Discussions in most articles. It has even been suggested [21] that $E$ can be regarded as a variable(!), though this novel 'definition' of $E$ was neither meaningfully described nor its applications and/or value explained. Lacking adequate theory, this static subject remains stagnant [20, 27].

Publications: Lack of literature reviews and of order within the thermoanalytical literature. (Self-)discriminatory publication policy

The accumulated set of Thermoanalytical Studies, TAS, publications include few, if any, comparative reviews or systematic surveys. These uncritical articles, with limited Introductions and superficial Discussions, lacking coherent, meaningful and adequate theoretical foundations, together with misleading misuses of kinetic terminology, have failed to exploit the potential of this topic. The rate data reported remain empirical. All these limitations of Thermoanalytical Studies, TAS [18-30], have remained unaddressed or, worse, have been wilfully ignored for decades, by the subject's most influential practitioners. In contrast, the present critical appraisal of the subject area is intended to be comprehensive, critical, realistic, fair and open-minded [28]. 
The TAS literature includes (uncounted!) calculated pairs of $\ln A, E$ magnitudes for innumerable, diverse reactants (see [34]). Some values reported by different workers for the same reactions are inconsistent. In an analysis of some 400 pairs of such published $(\ln A, E)$ values, no trends or correlations could be found [44]: $\log A$ had a 'preferred' value of around $10^{12} \mathrm{~s}^{-1}$, and $E$ values were 'fairly evenly spread' between 100 and $230 \mathrm{~kJ} \mathrm{~mol}^{-1}$. In several searches, no evidence of any systematic order could be found!

This 'non-finding' is consistent with the literature: apparently nobody else has yet identified systematic order within the available kinetic data. $\ln A, E$ values have not, so far, been correlated with the compositions or any physical property (enthalpy of formation, etc.) of the numerous, diverse reactants studied during decades of these studies. One (dictionary defined) objective of science is to identify systematic order within the observations made: this has not been achieved here. The second objective of science, to use the observations available to make meaningful predictions of expected behaviour for hitherto untested systems, also remains unrealised. On both criteria, Thermoanalytical Studies, TAS, cannot be regarded as having achieved the status of a science!

\section{Journals}

A majority of reports of Thermoanalytical Studies, TAS, have appeared in specialist journals including Journal of Thermal Analysis and Calorimetry, Thermochimica Acta (both launched around 1970) and others. At the same time, 'main-stream' chemistry journals have published very few articles featuring solid-state reactions. This is consistent with the overall argument presented here: the subject area is now effectively 'sidelined' and is of less (if any?) general interest to chemists than formerly. Workers in this field have evidently (and intentionally?) progressively self-isolated/detached the topic from its former role as an integral part of the chemical sciences.

This separation means that the distinctive methodology and theoretical models, routinely used in this subject, are unlikely to be queried by kineticists and other chemists qualified, and willing to challenge them. Effective formation of a 'sect' gives authors freedom to 'play by their own rules', deviating from generally accepted principles and shielded from outside criticism. This introverted policy is scientifically indefensible and should remind everyone that accepted scientific assumptions require periodic review and proposed novel alternative approaches need regular, meaningful and critical comparative reappraisal. This has clearly not been happening within the cosy thermoanalytical fraternity!

\section{Meaningless mathematical manipulations of minimalistic measurements}

This section exemplifies a few of the more unusual, unrealistic, features of thermochemical articles; these are discussed in greater detail, with supporting references, in [8, 18-30]. Other examples appeared in papers refereed by this author (some declined!). (Such unpublished material is also indicative of attitudes held and applied within the subject.)

Consecutive different but overlapping/concurrent rate processes Some thermoanalytical reports have used completely unacceptable methods of 'kinetic analyses': evidence that their author(s) did not understand basic reaction kinetics theory! For example, in some articles, $(\alpha-t)$ data were measured for an overall reaction and identified as consisting of two (or more) distinct, but different, consecutive and overlapping rate processes. Then this combined, two (or more) reactions $(\alpha-t)$, data set was knowingly 'kinetically analysed' by a single rate equation, giving a 'composite(?)' $E$ value. Totally unacceptable kinetics! However, and potentially more significant, is that automated data recording and analyses by computer programs may hide essential clues about the existence of two or more participating rate process. Similarly, when using DSC, this approach may fail to recognise an endotherm overlapping with reaction onset and so reactant melting is undetected. Again, overlapping rate processes may be analysed as a single reaction, particularly using non-isothermal methods. Careful perusal of 'raw data' is always profitable: much can be learned from scrutiny of isothermal $\alpha-t$ curves [4-8], perhaps during preliminary experiments, not always mentioned in thermoanalysis reports.

The compensation effect $(C E)$ The $\mathrm{CE}$ is a linear relationship between $\ln A$ and $E$ values sometimes found for a group of chemical reactions, usually closely related, or, as in situations discussed here, arising in kinetic analyses when using a set of different rate equations to analyse rate data for a single reaction $[44,45]$. Compensation of reaction rates, $k$, occurs because an increase in $E$ (thereby reducing $k$ ) is offset by a compensatory rise in $\ln A$. The effect is also termed isokinetic behaviour: at the isokinetic temperature, the rate, $k$ value, for all reactions within the set is identical $[35,43]$.

In many Thermoanalytical Studies, the set of $\ln A, E$ values, calculated for the target reaction, using the usual set of 20-25 rate expressions, often show a CE [8]. This may then be identified as an 'interesting' conclusion from the work, though the significance and value of such 'interest' are not usually explained. One possible reason, amongst others, is the use of the incorrect rate constant definition, $f(\alpha)=k t^{\mathrm{n}}$, instead of $f(\alpha)=(k t)^{\mathrm{n}}$. In this meaningless mathematical manipulation, or 'interpretation', any single data set is necessarily isokinetic! A 'deduction' of mathematical rather than chemical significance! 
Reactant selection Reactants identified as worthy of thermoanalytical investigation have been, on occasion, justified by: 'This substance has never previously been studied'. Not a compelling reason for the coherent, organic growth of any scientific topic!

Data accuracy Magnitudes of $E \mathrm{~kJ} \mathrm{~mol}^{-1}$ have been routinely reported to two (or more!) decimal places, implying unrealistic data accuracy and, despite using statistical methods, often omit: error limits, $a$-ranges for data fit, reproducibility tests of the data measured, etc. Calculations reported to excessive decimal places cannot increase data accuracy!

Survey of contents of articles [46-64], all citing references in references [18-30] (The initiative for this analysis is explained in Acknowledgements at the end of the article). Over three decades, articles [18-30] detailing the many shortcomings, limitations, errors, misconceptions, etc., typical and characteristic of Thermoanalytical Studies, TAS, were published. The content of these articles justifies and exemplifies the generalisations, made in this review, about the lack of responses to criticisms. This section surveys the more recent literature [47-64] to assess any later impact of these same criticisms. The conclusion is that all these censures and the novel, alternative theory, the thermochemical (CDV) approach, remain effectively ignored. This is inexplicable in a scientific subject. Two rival theories, formulated to explain the same phenomena, are unsustainable, unacceptable and demand consideration by everyone concerned, through comparative testing until one theory is identified as superior and the other, the confirmed and agreed 'looser', is then eliminated. That this has not happened is attributable $[21,22]$ to the unshakeable unwillingness of those active in the field to recognise the existence of both the rival theory and the theoretical inadequacies and errors pervading their own Thermoanalytical Studies, TAS.

Two articles, found in this literature search, as meriting mention are: (1) L'vov [30], summarising the 130 years of studies of solid-state thermal decompositions, also expresses the above point forcefully. Like me, he fails to understand why his contributions to the subject have remained ignored, not discussed. (2) Sestak [46], in one of the few recent thermoanalytical papers concerned with subject theory, discusses the continued relevance of the Kissinger equation and non-isothermal kinetic studies. This concerns thermal inertia in $E$ determinations and is thus not discussed here.

The contents and relevance of the other eighteen [47-64] articles to the criticisms levelled against Thermoanalytical Studies, TAS, are briefly commented upon and appraised below:

[47] Reference [18] is cited but CDV theory is not, cannot be, used in this largely empirical kinetic analysis of cassava starch degradation, for which both rate equation and $E$ show variations.

[48] Again [18] is cited but CDV is not applied. The controlling step in nickel oxalate decomposition is identified, from bond energy estimations, as $\mathrm{C}-\mathrm{C}$ rupture.

[49] Solid-solid transition nucleation steps are characterised by advanced microscopic techniques, not relevant here, except as emphasising the value of observational studies.

[50] The Friedman method is applied in investigating the thermal degradation kinetics of photonically cured electrically conductive adhesives. Although [18] is cited, the CDV method is (correctly) not applied to interpret the complex kinetic behaviour showing a 'variable $E$ ' [21] and a high 'reaction order', 4.07.

[51] Although [19] and a L'vov paper are cited, these are then effectively 'dismissed'. The multi-step decomposition of iron(III) phosphate dihydrate $\mathrm{FePO}_{4} \cdot 2 \mathrm{H}_{2} \mathrm{O}$ is described as 'complex' and $E$ variable [21]. Analysis is similar to usual practice in Thermoanalytical Studies, TAS, including the lack of supporting observations.

[52] The kinetic characteristics of pyrolyses of biomass constituents are discussed in the context of the many rate equations used here to interpret data. While [3, 27, 28, 42, 43] and 5 more of L'vov's articles are cited, CDV theory is inapplicable to the characteristic and numerous overlapping reactions contributing to the breakdowns of natural substances

[53] Unique amongst the recent relevant articles located in our search, this alone discussed aspects of the thermodynamic foundations of CDV theory. The detailed content is not repeated here, but no general conclusion is emphasised.

[54] Editorial, on Journal policy: React. Kinet. Mech. Catal., cites [28] and L'vov's papers.

[55] Citations of [3, 28] and two of L'vov's papers, transition state and CDV theories are discussed, but not compared. Both are difficult to reconcile with 'variable' and 'reliable' $E$ values [21] and related thermodynamic functions in this study of $\mathrm{LiCoPO}_{4}$ nanoparticle formation. We find no new insights into either kinetics or chemistry of these reactions.

[56] Although citing [28], this paper is concerned with melting points and volatilisation of the catalytic hydrogenation products of 1,4 bis(bhenylethynyl)benzene.

[57] This article on limestone decomposition in different atmospheres is notable for the remarkably wide range of 
$E$ values calculated, averages from 122 to $1112 \mathrm{~kJ} \mathrm{~mol}^{-1}$ (reported to three decimal places!). L'vov's important and detailed review [3] of this reaction, $\mathrm{CaCO}_{3}$ decomposition with and without $\mathrm{CO}_{2}$ present, is not cited.

[58] A study of the synthesis, spectral characterisation and thermal analysis of rubrocurcumin and its analogues. After noting that 'The elucidation of mechanism of a solid-state decomposition is a complicated one' (from a L'vov 2011 paper), kinetic data analyses follow the usual thermoanalytical methods, with few supporting observations.

[59] Kinetics and nucleation mechanism of formation of carbamazepine-saccharin co-crystals from ethanol solution. Not relevant here.

[60] A kinetic investigation of the thermal decomposition of 1,1'-dihydroxy-5,5'-bitetrazole-metal salts. The rate data analysis, according to the usual thermoanalytical methods, identifies kinetic behaviour as $n+g$ and other solid-state models. Possible initial melting (from DSC) is not confirmed by microscopy or otherwise and so this reaction is potentially inconsistent with the solid-state reaction models.

[61] The synthesis and thermal stability of cisdichlorool[ $(E)$-ethyo-2-(2-((8-hydroxyquinolin-2-il)methylene)hidrazinyl)acetate- $\left.\kappa^{2} N\right]$-palladium complex are investigated. This appears to be only a preliminary study, involving 'multiple overlapping endothermic and exothermic steps'. The data reported are (regarded here as) insufficient for kinetic analyses.

[62] The synthesis and thermal decomposition of neodymium(III) peroxotitanate. The three stages of reactant decomposition to $\mathrm{Nd}_{2} \mathrm{TiO}_{5}$ were expressed by three stoichiometric equations, described as the reaction 'mechanism'. No kinetic studies.

[63] Preparation of $\mathrm{ZnCo}_{2} \mathrm{O}_{4}$ nanoparticles, by a 'green' synthesis from an Aloe albiflora extract and its use as a catalyst for $\mathrm{NH}_{4} \mathrm{ClO}_{4}$ thermal decomposition. As usual, in Thermoanalytical Studies, TAS, this was a minimalist kinetic study with 'mechanistic' conclusions inadequately supported by few complementary observations.

[64] Unusually, this article reports an investigation of the, analytically confirmed, chemical steps participating in the thermal decomposition of fluoxethine. Thermogravimetric data were complemented by microscopy, DSC and gaseous products analyses. Reactant melted at $433 \mathrm{~K}$, but products did not solidify on cooling. No kinetic measurements were reported.
Discussion The articles [47-64], identified in my literature search as most likely to contain references to CDV theory, revealed only a single meaningful example [53]. Nine others [54, 55, 57-63] cite articles critical of Thermoanalytical Studies, TAS, mainly [27, 28] four each, [3, 43] one each, and six refer to several of L'vov's articles. However, none of these publications apply CDV concepts [3] to interpret kinetic data or make any (critical) comparisons with theory characteristic of Thermoanalytical Studies, TAS. Indeed, for many of the reactants discussed, such attempts would be inappropriate because these involve complicated and/or multiple rate processes and/or 'variable' $E$ values [21]. Such typical thermal degradations of natural substances, incompletely characterised reactants, invariably involve concurrent and/or overlapping consecutive reactions fitting different rate equations and/or $E$ values, etc.

We find, therefore, that fourteen of the articles published after 1984, drawing attention to the unacceptability of the theory currently used in Thermoanalytical Studies, TAS, remain effectively ignored and that the alternative CDV theory [3] has made virtually no impact (Quotes [31, 32]!). The unsatisfactory current state of solid-state thermal chemistry is found in papers characterised by the failure to apply appropriate kinetic principles rigorously (reflecting little credit on their authors). The present stagnant [20, 27], indeed moribund, state of the subject, is apparently now offering little satisfaction to researchers and to investing supporters, accounts for its recent decline.

An additional, more recent, survey was made of about two hundred articles appearing in J. Therm. Anal. Calor. and Thermochim. Acta (Dec. 2018-Feb. 2019). No investigations of the thermal decompositions of single compounds, of the type previously so popular, were found. Instead, thermoanalytical methods are now being used to study the breakdown stoichiometries of a wider range of more diverse reactants including complex organic compounds, mixtures of metallic and oxide phases, polymeric materials and others. Moreover, these later Thermoanalytical Studies are being complemented with appropriate analytical measurements, although microscopy still rarely features. In such investigations, $E$ values are reported (still with unrealistic 'accuracies'). It appears that the subject focus has moved on to more complex reactants and reactions less amenable to mechanism elucidation by kinetic methods, but studies now tend to include product identifications.

Solid-state thermal reactions remain a subject of potentially considerable chemical and technological/commercial interest. Thermoanalytical researchers (if they remain active [31, 32]!) have shown their unwillingness either to revise their opinions, prejudices or to face up to the challenge of comparisons with the CDV approach. So now the hope is that others, disregarding past errors, will see this as a topic ripe for development and move into this promising subject 
area. During the four decades of unsuccessful Thermoanalytical Studies, TAS, advances have been made in other branches of chemistry: theory has developed, and more powerful equipment and computing methods have appeared and may be imaginatively applied to progress rapidly this auspicious, but long stagnated, sidelined branch of science. A primary motive for this article is the wish to publicise, to main-stream chemists (i.e. those outside the 'cul-de-sac'), this potentially fruitful 'Gap in the Literature', which offers stimulating challenges to advance both fundamental chemical science and reactions of potential economic value: a topic to excite, examine, explore, expand, explain, extol and exploit!

\section{Heterogeneous catalysis: a brief consideration of selected kinetic features}

This short survey of selected features of heterogeneous catalytic reactions focuses on their kinetic characteristics and, in particular, the roles of adsorbed participants. These merit consideration here because, perhaps unexpectedly, they share some mechanistic features with those discussed above for solid-state thermal reactions. For both, the relationship between rate constant, $k$, and $T(\mathrm{~K})$ is adequately expressed by the Arrhenius equation [45]. However, again, for reactant precursors retained at, on or within the surface of a catalytically active solid, freedom of movement may be restricted and so the 'free-flying', reaction precursors of the homogeneous Arrhenius-type reaction model is inapplicable. Chemisorbed reactants and intermediates may possess reduced ability to migrate across solid surfaces or, alternatively, may be immobilised at adsorption sites. Either way, the reaction steps, including those determining overall rate, may more closely resemble those controlling solid-state rate processes than those of homogeneous chemical reactions. Consequently, the Arrhenius model does not quantitatively or mechanistically represent reactions involving the participation of solids.

As with solid-state thermal reactions, no systematic trends, relating the numerous $\ln A, E$ magnitudes reported for heterogeneous catalytic reactions, to any thermodynamic features of the reactions/reactants have been identified in the literature. However, in parallel with theory for solidstate thermal decompositions, this situation was similarly changed by the recognition that the CDV reaction model, the thermochemical CDV approach (discussed below), is equally applicable to at least two heterogeneous catalytic reactions [42]: the oxidations of $\mathrm{H}_{2}$ [65] and of $\mathrm{CO}$ [66] on platinum metal (also, for a solid-gas reaction, the reduction of $\mathrm{NiO}$ by $\mathrm{H}_{2}$ [67]).

Another, much less significant, parallel between these reaction types is that both show compensation behaviour
$[43,45]$. This may be because all data in the $\ln A, E$ plots, i.e. those defining the 'compensating reaction set', are often approximately isokinetic, having been measured, for experimental convenience, within similar $k$ and $T$ ranges.

A significant difference between the two reaction types is the influence of gas pressures within the reaction zone on reaction rates. For solid-state decompositions, systematic variations of $k$ with ambient product pressures may indicate that a volatilisation step participates in reactant breakdown. However, in heterogeneous catalytic reactions there may be three (or more) steps to, on and off the active solid surface, assuming reactants to have unhindered access both to and from the active surfaces:

$$
\begin{aligned}
& \text { Reactant(s) adsorption(s) } \rightarrow \text { Surface reaction(s) } \\
& \quad \rightarrow \text { Reactant(s) desorption(s) }
\end{aligned}
$$

In principle, each of these could be rate limiting and influenced, directly or indirectly, by the prevailing pressure(s) of the gas(es) in the immediate vicinity of the catalyst surfaces.

The early literature [68], not reviewed here, then mainly focussed on extended metal surfaces, discusses mechanistic explanations for the observed kinetic characteristics of many heterogeneous catalytic reactions. Proposed reaction models include species adsorbed on 'chessboard'-type surfaces, consisting of regular crystallographic arrays of potential bonding sites. Chemical interactions were envisaged as occurring either between chemisorbed neighbours (Langmuir-Hinshelwood mechanism, $\mathrm{L}-\mathrm{H}$ ) or between chemisorbed species and gaseous reactant(s) (Eley-Rideal mechanism, E-R). Factors capable of influencing the temperature dependence of a heterogeneous reaction rate are discussed in [68, 69]. However, without more complementary evidence than is usually available, few insights into the reaction mechanism can be deduced from a calculated $E$ value, for reasons including:

1. In the $\mathrm{L}-\mathrm{H}$ mechanism, when modelled by adsorption of two reactants (A and $\mathrm{B}$, pressures: $p_{\mathrm{A}}$ and $p_{\mathrm{B}}$ ), both according to the Langmuir isotherm, the parameters $K_{\mathrm{A}}$ and $K_{\mathrm{B}}$ and the reaction rate constant, $k$, are all temperature dependent.

Reaction rate $=\frac{k K_{\mathrm{A}} K_{\mathrm{B}} p_{\mathrm{A}} p_{\mathrm{B}}}{\left(1+K_{\mathrm{A}} p_{\mathrm{A}}+K_{\mathrm{B}} p_{\mathrm{B}}\right)^{2}}$

Thus, [68]: 'the reaction rate is unlikely to be proportional to $\exp (-E / R T)$ '.

2. In the E-R mechanism, one reactant is adsorbed (with or without mobility) and the other is 'free-flying', and thus, its energy distribution is expressed by the Arrhenius model. However, the overall rate may also be influenced by any energy barrier to product formation and 
by the temperature variation of surface coverage by the adsorbed participant(s).

3. Although most heterogeneous reactions are believed [68] to occur by the $\mathrm{L}-\mathrm{H}$ mechanism, these alternatives probably represent limiting types, some reactions occupying intermediate positions.

4. Additional complications, modifications of catalytic activities and surface properties result from influences of surface impurities, promoters and/or poisons. Alkali metals alter work functions of $d$-metal surfaces, thereby significantly changing catalytic properties [69].

As in Thermoanalytical Studies, TAS, the significances of Arrhenius parameters calculated for heterogeneous catalytic reactions remain uncharacterised. Within the published In $A, E$ magnitudes, systematic order and reliable predictive capacity have never been identified [44], again showing the absence of scientific features in this topic, a serious limitation.

Some (restricted) insights into the chemistry of reactions occurring on platinum metal catalysts were found in the demonstration that surface textural changes occur during the oxidation of $\mathrm{CO}$ on $\mathrm{Pt}$ surfaces. It has long been known that, during the initial 'conditioning' of a platinum wire, its catalytic activity significantly increases [70]. Microscopic examinations of Pt catalysts showed $[70,71]$ that, before use, metal surface textures were rough and featureless. However, after use for $\mathrm{CO}$ oxidation, wire surfaces exhibited the planar, flat surfaces typical of etched crystallographic faces, including 'pits and hills', sizes around $0.1-1.0 \mu \mathrm{m}$, bounded by oriented planes. This observational evidence demonstrates the movement of surface Pt atoms during reaction, attributable to the intervention of mobile adsorbed intermediates (presumably), surface compounds containing $\mathrm{O}$ and C. Later, after gaseous product desorption, the metal atoms so released become re-accommodated into the metal preferentially at surface step edges, resulting in growth of the flat, low-index crystal planes observed microscopically.

The (successful) application of the thermochemical CDV approach to this reaction [66], raises the possibility that the participation of a transient volatilisation step (desorption of $\mathrm{PtO}_{2}$ ) could result in Pt loss from the catalyst. Semiquantitative estimations suggest that, under the conditions considered, these would be extremely small: the ratio of $\mathrm{CO}_{2} /$ $\mathrm{PtO}_{2}$ molecular yields being some 4-5 orders of magnitude. Platinum loss during catalysed reactions is an effect worthy of further investigation.

Aspects of a recent literature survey A survey of articles in recent issues of Catalysis Reviews and Journal of Catalysis (Jan-Feb 2019) shows that current research effort is being directed towards developing new catalyst types with diverse and novel compositions. Components are often highly dispersed, some containing two or more types of active catalytic sites. Examples include imaginative combinations of metals and of oxides (etc.), some very finely dispersed on acidic surfaces, on zeolites and/or on high-area clays (e.g. montmorillonite), on metal-organic frameworks, etc., sometimes including the influences of radiation. Many such investigations address environmental, industrial and/or commercial objectives: the processing of natural, high molecular weight feedstock, efficient catalyst uses and reuses, reducing diesel exhaust pollution, etc. Such studies often determine reaction stoichiometries and product yields, though the reactions involved are often too complicated to allow mechanisms and rate controls to be elucidated easily, if at all.

One overall trend is towards ever-greater catalyst dispersal, including the use of nano-sized particles of metals, metallic oxides, etc., on high-area, active supports. Ultimately, this more efficient use of some expensive active materials can be regarded as moving towards a blurring of the distinction between heterogeneous and homogeneous catalysis. Moreover, the increasing numbers and types of surface sites directly, or indirectly, participating in many of the reactions now attracting interest make it difficult, even impossible, to use kinetic studies to elucidate mechanisms. This recent literature was found to include few references to rate studies or to theory advances: both directly attributable to the complexity of reactants, catalysts and/or reactions now attracting interest.

Consequently, and for quite different reasons, currently both Thermoanalytical Studies, TAS, and heterogeneous catalytic studies appear to be moving away from the kinetic approach to establishing rate controls and mechanisms for reactions investigated.

\section{The L'vov thermochemical (CDV) approach to rate data interpretation for thermal reactions involving solids: decompositions and heterogeneous catalysis}

The thermochemical approach to rate data interpretation for thermal reactions of solids, developed and applied by L'vov, is a prime example of the profitable cross-fertilisation of ideas between two very different branches of chemistry. During studies of reactant sample (analyte) volatilisations, for electrothermal atomic absorption analyses [3, 42, 43] L'vov recognised the possibility that similar reactant volatilisation rate controls might apply in thermal decompositions of both solid and of liquid reactants. L'vov was unconstrained by (self-imposed) practices, seemingly agreed by Thermoanalytical Studies, TAS, practitioners: always avoid consideration of any possibility of a phase change during these reactions and invariably accept the validity of the (homogeneous) Arrhenius reaction model (my 'Quote'). 
Unlike the thermoanalytical 'solid-state' scientists, L'vov, having an open mind and after researching, extensively and quantitatively(!), the volatilities of many diverse analytes used in spectrometric analyses, realised that, though small, the vapour pressures of appropriate solids were, nevertheless, sufficient to account for their participation in thermal decompositions (Chap 5 of [3]). Development of this 'thermochemical approach' $[3,29,30]$ gives us the Congruent Dissociative Volatilisation (CDV) mechanism of solid-state thermal decompositions which, as outlined below, also finds applications to heterogeneous catalytic reactions, the oxidations of $\mathrm{H}_{2}$ and of $\mathrm{CO}$ on Pt metal $[65,66]$.

Congruent Dissociative Volatilisation (CDV) mechanism of thermal decompositions Significant features of CDV theory, which merit its application in interpreting kinetic data for many solid-state thermal reactions, are outlined. It is not appropriate to re-present CDV theory in full here because it is already readily accessible and comprehensively explained with numerous examples, particularly in [3, 42, 43]. These publications include the thermochemical calculations, together with supporting references, relating the arguments to the wider, relevant chemical literature much more closely and thoroughly than is customary in many chemical publications. However, recognising the widespread refusal of almost all thermoanalytical researchers to acknowledge the very existence of $\mathrm{CDV}$, the account given here specifically addresses features of this novel theory which we suspect, or guess, they misunderstand, reject as unacceptable or simply choose to ignore, presumably feeling more comfortable with their simpler (but incorrect!) theory.

Reactant Volatilisation L'vov distinguishes [3] two alternative reaction types that may arise on heating a solid or liquid reactant, $R$ :

$R(s / l) \leftrightarrow A(s)+B(g) \quad$ Incongruent dissociative volatilization (IDV)

This is seen as incomplete for the rate processes considered, because the structure of solid product, $A(s)$, may differ from that of the reactant, requiring an additional step. Moreover, this model, underlying thermoanalytical theory, has failed, over decades, to introduce order into the extensive thermochemical literature. The alternative is:

$R(s / l) \leftrightarrow A(g)+B(g) \quad$ Congruent dissociative volatilization(CDV)

and where a low-volatility product is condensed:

$R(s / l) \leftrightarrow A(g)+B(g) \rightarrow A(s)+B(g)$

This CDV approach has remained unconsidered by thermoanalysts, apparently adhering to their doctrinaire view that 'such reactions can occur only in the solid state'. The fact is, as L'vov has unequivocally and quantitatively demonstrated, heated solids do exert appreciable vapour pressures. Moreover, the Hertz-Langmuir vaporisation equation ([3] p.
37) can be applied to the sublimation/dissociative vaporisation rate (during a steady-state reaction mode, e.g. the deceleratory phase of an isothermal $\alpha-t$ curve). This enables the equilibrium partial pressures of such vaporised products to be related to thermodynamic quantities for this reaction, enthalpy and entropy. Although, for many solids, such equilibrium pressures are small, this analytical approach has enabled the absolute rates of solid decompositions for many solid reactants to be calculated, using thermodynamic data and CDV theory [3]. Moreover, this approach has revealed systematic order, relating kinetics of sublimations and dissociations of solid reactants to their thermodynamic properties for many and diverse compounds, including oxides, hydroxides, clays, sulphates, carbonates etc. (see Chap. 16 of [3]). Such chemical insights and correlations had never previously been achieved by the extensive and prolonged Thermoanalytical Studies, TAS.

Chapter 5 of [3] discusses the relationship between the $E$ value calculated for a solid-state thermal decomposition and the reactant vaporisation enthalpy. Such comparisons are possible only for reactants for which sufficient, reliably measured kinetic data are available. These stringent requirements exclude many or, more realistically, most published Thermoanalytical Studies, which lack evidence about the occurrence, or otherwise, of melting, intermediate formation, etc.

The form of the ln $k-K / T$ relationship in CDV theory is identical with the Arrhenius expression, so that (unfortunately!) kinetic criteria alone cannot distinguish between these alternative reaction rate controls: activation of a specific reactant bond or reaction precursor volatilisation. However, because the CDV model can be related to the reactant's thermodynamic properties, it is much preferred for interpretation of rate data, whereby this theoretical explanation provides chemical insights into solid-state decompositions: the step controlling reaction rate and mechanism. Such insights were never achieved in decades of Thermoanalytical Studies, TAS. Therefore, the thermochemical CDV approach is strongly recommended here for wider, indeed general, application.

Again, the maintained use of two rival theories for this reaction type represents an untenable, scientifically 'unstable', situation, demanding detailed comparative appraisals to determine which should prevail. The present bizarre situation, whereby (prejudiced) expert researchers, seemingly purposefully, maintain a long-stagnant subject [20, 27], must be recognised and steps taken to promote this subject's advancement.

Influences of prevailing product gas pressure( $s$ ) on reaction kinetics Rates of evaporation processes, in which products leaving a solid surface may equilibrate with gases present, are expected to be influenced by these prevailing gas pressure(s) and, indeed, such trends are found [3], though 
rarely (if ever) sought, or even mentioned, throughout the Thermoanalytical Studies, TAS, literature. L'vov distinguishes two situations, both of which require consideration in rate data collection and interpretation. For reactions in the isobaric mode, the prevailing pressure of gaseous product exceeds equilibrium value and remains unchanged during kinetic measurements. In the equimolar mode, the prevailing pressure of primary product is below the equilibrium value, or zero, and again remains constant. The roles of these kinetic influences in data interpretation are illustrated by the two examples below, explained in detail in [3].

Carbon monoxide oxidation on Pt: a review of kinetic studies for this reaction identified 31 values of $E, 17$ being between 100 and 138, mean $116 \mathrm{~kJ} \mathrm{~mol}^{-1}$ [66]. This has previously been alternatively ascribed to the desorption energy of $\mathrm{CO}$ from $\mathrm{Pt}$ or to the activation step for $\mathrm{CO}$ interaction with $\mathrm{O}$. The enthalpy change, $\Delta_{\mathrm{r}} H_{\mathrm{T}}^{\mathrm{o}} / \mathrm{kJ} \mathrm{mol}^{-1}$ calculated for the reaction $\mathrm{PtO}_{2}(\mathrm{~s})+2 \mathrm{CO}(\mathrm{g}) \rightarrow \mathrm{Pt}(\mathrm{g})+2 \mathrm{CO}_{2}(\mathrm{~g})$, in the isobaric mode (prevailing product gas pressure exceeding the equilibrium value), is $129 \mathrm{~kJ} \mathrm{~mol}^{-1}$ and satisfactorily agrees with the above mean value. Moreover, another four literature values, $48-54 \mathrm{~kJ} \mathrm{~mol}^{-1}$, were from lower temperatures reactions, $<400 \mathrm{~K}$, for the equimolar mode (prevailing product gas pressure below its equilibrium value). In this pressure range, $\Delta_{\mathrm{r}} H_{\mathrm{T}}^{\mathrm{o}} / \mathrm{kJ} \mathrm{mol}^{-1}$ is calculated as $43 \mathrm{~kJ} \mathrm{~mol}^{-1}$ and again the agreement is acceptable. The novel reaction mechanism in this thermochemical approach differs fundamentally from the surface (LH or ER) mechanisms mentioned above. The first step is the rate of $\mathrm{CO}$ oxidation: $\mathrm{PtO}_{2}(\mathrm{~s})+2 \mathrm{CO}(\mathrm{g}) \leftrightarrow \mathrm{Pt}(\mathrm{g})+2 \mathrm{CO}_{2}(\mathrm{~g})$. The second step is the rate of $\mathrm{PtO}_{2}$ surface layer renewal: $\mathrm{Pt}(\mathrm{g})+\mathrm{O}_{2}(\mathrm{~g}) \leftrightarrow \mathrm{PtO}_{2}(\mathrm{~g})$ $\rightarrow \mathrm{PtO}_{2}(\mathrm{~s})$. This model enables the absolute reaction rate to be calculated thermochemically and accounts for both the surface retexturing observed $[70,71]$ and the (possible?) [66] small Pt catalyst metal losses during this reaction (mentioned above).

This approach has also been successfully applied to the CDV model for catalytic oxidation of hydrogen on Pt [65]. The proposed mechanism again proceeds in two similar steps: the first controlling $\mathrm{H}_{2}$ oxidation rate: $\mathrm{PtO}_{2}(\mathrm{~s})+2 \mathrm{H}_{2}(\mathrm{~g}) \leftrightarrow \mathrm{Pt}(\mathrm{g})+2 \mathrm{H}_{2} \mathrm{O}$ and the second the rate of $\mathrm{PtO}_{2}$ surface layer renewal (as previously): $\mathrm{Pt}(\mathrm{g})+\mathrm{O}_{2} \leftrightarrow \mathrm{PtO}_{2}(\mathrm{~g}) \rightarrow \mathrm{PtO}_{2}(\mathrm{~s})$. The greater activity of $\mathrm{Pt}$ in promoting $\mathrm{H}_{2}$ oxidation than for $\mathrm{CO}$ and the thermochemical analyses are discussed in [65]. Again, the merit of this approach in elucidating rate controls and reaction mechanisms for the heterogeneous catalytic reactions (and also for reduction of a solid oxide, $\mathrm{NiO}+\mathrm{H}_{2} \rightarrow \mathrm{Ni}+\mathrm{H}_{2} \mathrm{O}$ [67]) is vindicated.

Nucleation and growth, leading to geometric kinetics An independent observer, surveying this general field, could well regard it as two distinctive, even separate, topics. (1) Thermoanalytical Studies, TAS: kinetic analyses used to identify (from 20-25 non-uniform rate equations) the 'best kinetic fit': i.e. 'reaction mechanism', usually unsupported by complementary studies, sometimes including an $E$ interpretation of speculative mechanistic significance only. (2) In contrast, the CDV, thermochemical approach analyses the 'established' reaction rate, i.e. during a steady-state mode (e.g. the deceleratory phase of an isothermal $\alpha-t$ curve, mentioned above) to enable insights into reaction controls. These latter publications focus on processes within the reaction zone, without consideration of the overall kinetic behaviour, including the geometric controls.

In passing, we suggest that this omission from the CDV literature, of the familiar ' $n+g$ ' background, a dominant theme throughout most of the solid-state reaction literature, may (possibly?) explain the reluctance of some researchers to engage positively with the thermochemical CDV approach. Nevertheless, the two essential features of solidstate reactions, nucleation and growth, are discussed in [3] (and above), also elsewhere in L'vov's many publications.

\section{Aspects of solid-state thermal decompositions that are not, or poorly, understood include}

Precursor Reactions For some solid-state reactants, decomposition may be preceded by an initial deceleratory process representing only a small product yield, often $1-2 \%$. This is usually attributed to reactions of surface impurities, superficial water, surface deterioration during storage, etc. Moreover, constituents of outermost crystal layers are less stable than those within the solid and products escape more easily. Currently, we know little about if or how such surface reactions participate in or contribute to the subsequent nucleation step(s). A recent study [72] appears particularly promising.

Examples of initial precursor reactions include: after the onset of $\mathrm{KMnO}_{4}$ decomposition, a thin outer 'skin' of unknown composition and structure readily detaches to reveal nuclei beneath [73]. During copper(II) malonate [74] decomposition, 'preserved' and coherent outer surfaces maintain the individualities of reactant crystallites, inside which there is internal melting, with the formation of a molten acetate intermediate. These surface features of reactant crystals remain, as yet, uncharacterised.

Nucleation Little is known about the earliest stages of nucleation wherein a precursor site, of locally enhanced reactivity, ascribed to structural disorder, surface damage and/or impurities, etc.[4-8], is transformed into a germ (lessstable) nucleus. This later stabilises into the (more robust) advancing interface of a growth nucleus. Techniques, including microscopy, much improved since the early studies [5, $6,8,72]$, may now enable insights into these reaction-initiating steps. Again, different types of change may occur in different reactants and three, or more, stages may require 
characterisation. These are: (1) surface layer modifications prior to reaction, e.g. potassium permanganate [73] and copper(II) malonate [74], above; (2) the initial nucleation processes, at crystallographic imperfections etc. at, on or in reactant surfaces [4, 6-8]; and (3) the subsequent transition step(s) from germ to growth nucleus, enabling reaction to continue in the CDV-applicable regime [72].

L'vov [3], pp. 19-21, identifies the transition from the initial, small, slow-growing germ nucleus into a growth nucleus as occurring when the interface of a developing nucleus has reached the stage whereby a proportion of the energy released on condensation of the low-volatility product can contribute to reactant volatilisation. This accounts for the preferential reaction at reactant/product interfaces, replacing the earlier strain and/or autocatalysis assumptions, mentioned above, another unresolved feature which might possibly be further investigated by high-resolution microscopy [72].

While this assumption explains the behaviour pattern observed, it is a concept that is likely to be difficult to confirm! It can also be expected to be challenged and will, no doubt, be a subject for future debates! Microscopic evidence could have value here in characterising the paths, and possibly ease of escape, of gaseous products leaving active reaction zones, through the intranuclear crack structures permeating the (often reduced volume of) residual product(s) [75-77]. Few of the reactants included in the accounts of successful applications of CDV theory, [3] Chap. 16, have yet been subjected to detailed microscopic examination of interfaces and accompanying textural changes. Such studies may yet yield further chemical insights into these reaction steps.

Comments on aspects of the current situation Four decades of Thermoanalytical Studies, TAS, have left significant 'Gaps' in our understanding of the chemistry of solid-state decompositions. However, CDV theory [3] now provides thermochemical insights into the factors controlling the advance rate of established, growth interfaces into reactants, based on carefully measured, reliable kinetic data for wellcharacterised reactants and reactions.

'Quo vadis': What is the way forward? Identifying ways in which this subject might be 'reinvented' for development by a new generation of innovative researchers is challenging. We hope that the above summary of the older literature, with [4-9], provides some useful background information, including the development of topological solid-state reaction models, subsequently widely used. Nevertheless, the many remaining unresolved features of the chemistries of these types of reactions still offer interesting problems to a new generation of open-minded researchers. Unprejudiced by past errors and shortcomings but willing introduce new ideas, they can be expected to resume advancing our understanding of this over-long stagnated subject $[20,27]$.
The considerable progress made by both chemical theory and experimental methods, during the past four decades of diminished progress, can now be imaginatively exploited to find novel ways of increasing our understanding of the chemical controls and mechanisms of solid-state reactions.

The Thermoanalytical Studies, TAS, literature offers little, if anything, of value here and can safely be ignored. (Though some readers may wish to satisfy themselves of the superficiality of these studies!).

However, before solid-state thermal chemistry can advance, it is essential that its present situation is comprehensively appraised to establish reliable, stable underlying foundations. Achieving this will require significant investment of time and effort. A first necessity is for independent researchers to critically and fully appraise L'vov's CDV theory together with the assumptions underlying it, including the observational data upon which it is based [3]. It is also important that, before this novel chemical principle can be generally applied, consensus agreement is reached about its acceptability, validity and applicability ranges, together with demonstrations of its successful applications in further, hitherto untested, systems. Other crucial features, also necessitating examination and agreement, include the novel concept that the 'autocatalytic growth' of nuclei results from energy transferred back onto the reactant solid by species condensing (mentioned above). This replaces the earlier explanations of interface strain and/or autocatalysis.

Much of the present CDV literature, while rigorous and thorough, is probably not easily or readily understood by many chemists, appearing to be implicitly addressed to mathematics and physics-trained scientists. There is, therefore, a real need to re-present CDV theory in a simplified form, more palatable to chemists. Another 'chasm' worth bridging is that separating conventional models of $n+g$ topological reactions and CDV-type treatments.

\section{Experimental approaches to elucidate the thermal chemistry of initially solid reactants}

Having been highly critical of Thermoanalytical Studies, TAS (above), this reviewer wishes to demonstrate clearly, with examples, that much about thermal chemistries of decompositions can be learned using traditional laboratory methods. Supporting this claim, representative systems from the reviewers laboratory are cited, outlined and discussed below. Relatively few others have worked in this field of mechanistic chemistry. Such investigations require significantly more input (often including microscopy and analytical measurements) than the minimalistic Thermoanalytical Studies, TAS. These selected illustrative examples characterise the breakdown pathways for thermal decompositions of 
some relatively simple reactants: transition metal carboxylates and ammonium salts.

Microscopy Direct microscopic observations of reactions are effectively useless throughout most of chemistry. Thus, unfamiliarity is a probable reason why chemists so rarely exploit this resource. However, solid-state reactions are an exception to this generalisation [4-8], though its value is all too rarely appreciated. Microscopy provides us with (almost 'privileged') insights into solid-state reactions. Nevertheless, thermal analysts rarely, if ever, use visual or optical methods, implicitly preferring their automated kinetic analysis approach. Observations of growth nuclei for partly decomposed or dehydrated crystals provide both a more efficient and a more conclusive identification of (what they term) the 'reaction mechanism' than that indirectly interpreted from kinetic data. An interesting example of 'Black-Box' chemistry: the (printed) output from a machine is regarded superior, 'more reliable?' than that directly seen by eye! For this chemist, this is yet another inexplicable aspect of Thermoanalytical Studies, TAS. This welcome ability to 'see' chemical changes in solids has, all too rarely, been seized upon.

Another valuable feature of microscopic observations is the ability to identify reactant melting before breakdown. Thus, an isothermal reaction showing a sigmoid-shaped $\alpha-t$ curve can be characterised either as a $n+g$ process or as melting accompanied by reaction in the molten phase. Electron microscopes can also be used [75-77] to gain insights into $n+g$ reactions. Occasionally, the appearance of a metallic mirror is evidence of decomposition of a volatilised intermediate, e.g. copper(I) formate from copper(II) formate [78].

Product analyses, qualitative and quantitative The full characterisation of a thermal decomposition with the intervention of intermediates necessitates analytical identification of all compounds participating, supported by their measured concentrations across an appropriate range of $\alpha$ values. A listing of useful types of qualitative and quantitative analytical methods is unnecessary here, being already familiar to most chemists. (We notice, in passing, that L'vov played an important role [3] in developing atomic absorption analysis, potentially valuable for such analyses, while this same research programmes led to the foundation of his thermochemical approach, the CDV model. See above.)

\section{Representative mechanistic studies of 'initially solid-state' thermal decompositions}

Transition metal carboxylates: copper(II) carboxylates Isothermal kinetic studies of the thermal breakdown of copper(II) malonate [74] showed reaction was completed in two steps. The appreciable rate reduction at about $\alpha=0.5$ was attributed to stepwise cation reduction:
$\mathrm{Cu}^{2+} \rightarrow \mathrm{Cu}^{+} \rightarrow \mathrm{Cu}^{0}$ : confirmed analytically by measuring $\mathrm{Cu}^{2+}$ contents in reactant samples partially decomposed to known extents, without the formation of metallic copper. Analytical (n.m.r.) measurements showed that the amounts of acetate intermediate in partially decomposed reactant increased with $\alpha$, up to $\alpha=0.5$, thereafter decreasing. The second rate process was copper(I) acetate decomposition.

The first stage of this reaction, $\mathrm{Cu}^{2+} \rightarrow \mathrm{Cu}^{+}$, was acceleratory throughout, within crystals retaining their pseudomorphic individualities. Electron microscopic observations for (cooled) cleaved reactant crystals, previously decomposed to known extents, $\alpha$, showed that during this first cation reduction step, a viscous melt with a froth-like texture was formed within each crystal, the amount increasing with $\alpha$. The bubble-like internal texture is ascribed to evolution of product gases, $\mathrm{CO}_{2}$ with some $\mathrm{CO}$, within a molten malonate-acetate mixture. The second step finally yielded, at $\alpha=1.0$, residual particles of metallic copper dispersed on a carbonaceous residue. The reaction mechanism is discussed in detail, with supporting evidence and illustrations, in [74].

Copper(II) maleate and copper(II) fumarate thermal decompositions are reported in [79]. Again, both these kinetically studied reactions involve stepwise cation reduction. The first acceleratory step is accompanied by reactant melting, confirmed microscopically. Analytical evidence showed that the maleate anion first isomerised to fumarate, so that the second rate process was decomposition of copper(I) fumarate.

Kinetic characteristics of three crystal modifications of anhydrous copper(II) formate were compared: the relatively complicated mechanisms are discussed in detail in [8] pp. 443-445 and [78]. Again, all three reactions showed stepwise cation reduction, the resulting copper(I) formate being sufficiently volatile to decompose in the gas phase, depositing a metallic mirror, $\mathrm{Cu}^{0}$, in the glass apparatus outside the hottest reaction zone. Thus, melting is not the only phase change requiring consideration in thermal studies. Similar cation/metal mobility was seen during copper-catalysed decomposition of formic acid [80].

Transition metal carboxylates: nickel dicarboxylates Isothermal kinetic studies of the thermal decompositions of nickel malonate [81], nickel fumarate [82] and nickel maleate [83] showed all three were $n+g$ processes. It was (implicitly) assumed that $\mathrm{Ni}^{2+}$ did not undergo stepwise reduction. Microscopic observations showed no evidence of melting. Product analyses identified the products as $\mathrm{CO}_{2}$ and nickel carbide, excepting the maleate which yielded a finely divided $\mathrm{Ni} / \mathrm{C}$ residual mixture. The decomposition of nickel malonate [81] was dominated by a prolonged constant rate, zero order, rate process, $0.2<\alpha<0.9$, during which product nickel carbide grew through the thickening of parallel lamellae traversing the hexagonal plate-like reactant crystals, identified microscopically. Reaction of Ni fumarate [82] 
was predominantly a sigmoid-shaped $\alpha-t$ curve. Following a short acceleratory phase, the decomposition of nickel maleate [83] was thereafter deceleratory: this was attributed to continual nucleation of small particles of product $\mathrm{Ni} / \mathrm{C}$ on undecomposed reactant crystallites of progressively diminishing size.

These observations reveal nothing about the mechanisms of anion breakdown. It is likely that the well-known catalytic properties of nickel promote carboxylate decomposition at advancing salt/product interfaces. Progress towards elucidating the chemistry of these reactions may now be possible. One approach could be to compare these reaction rates, $k$, ln $A$ and $E$ with kinetic data for nickel-catalysed breakdowns of each dicarboxylic acid. Another is the use of higher power microscopy (not available to us in 1967-1970).

Ammonium dichromate Decomposition of $\left(\mathrm{NH}_{4}\right)_{2} \mathrm{Cr}_{2} \mathrm{O}_{7}$ was initiated at a number discrete local sites (previously and incorrectly reported as $n+g$ ), which microscopic examination identified as a liquid. Its froth-like texture was attributed to bubble formation [84]. Closely similar textural features appeared on heating $\mathrm{CrO}_{3}(1)$ in an atmosphere of $\mathrm{NH}_{3}+\mathrm{H}_{2} \mathrm{O}$ or (2) when mixed with $\left(\mathrm{NH}_{4}\right)_{2} \mathrm{CO}_{3}$. Because $\mathrm{CrO}_{3}$ melts just below the temperatures studied for all three reactions, the identical textures are ascribed to ammonia oxidation in liquid $\mathrm{CrO}_{3}$.

Ammonium perchlorate The thermal decomposition of $\mathrm{NH}_{4} \mathrm{ClO}_{4}$ must be classed as one of the most complicated solid-state thermal reactions ever investigated, with the reports probably being amongst the most numerous $[7,8,13$, 85-87]. The 'low-temperature' decomposition, <ca. $600 \mathrm{~K}$, is a $n+g$ reaction that ceases, after loss by decomposition of (only) about $30 \%$ reactant mass, giving a porous residue chemically identical with the original reactant, possibly a unique type of reaction. Furthermore, kinetic behaviour changes across a crystallographic transformation at $513 \mathrm{~K}$. At higher temperatures, $>c a$. $600 \mathrm{~K}$, decomposition proceeds to completion. In addition, all these rate processes are accompanied by salt sublimation, particularly in low ambient pressures. Meaningful insights into these reaction mechanisms cannot be obtained from the limited observations provided by kinetic or Thermoanalytical Studies.

Optical microscopic observations confirmed $n+g$ behaviour for the low-temperature reactions but provided no further useful information. However, using the greater magnifications of electron microscopy, sections across nuclei revealed [87], for reactant surfaces exposed by cleavage after partial reaction, the textures of the 'product' (chemically unchanged $\mathrm{NH}_{4} \mathrm{ClO}_{4}$ ) within and across advancing nucleus 'boundaries'. The outermost 'reacted' zones of nuclei were penetrated by deep grooves inward from original crystal surfaces. Deeper within each nucleus were interconnected networks of narrow, labyrinthine pores, diameters around $1.0 \mu \mathrm{m}$. While the approximately hemispherical nuclei boundaries were consistent with the kinetic $n+g$ behaviour, the reaction 'interfaces' were quite different from others typical of solid-state decompositions. Consequently, attempts to explain these observations had to be focussed on chemical considerations.

Analyses of partially, 'low-temperature' decomposed, reactant identified the presence of oxidised nitrogen. Kinetic and electron microscopic observations confirmed [87] that added ionic nitrates substantially accelerated ammonium perchlorate breakdown. From this and supporting observations, it was concluded that nitryl perchlorate was the most probable molten, unstable intermediate, also known to decompose at about $470 \mathrm{~K}$ with a similar activation energy. Thus, the low-temperature decomposition of this solid is explained by reactant breakdown occurring within thermally unstable molten droplets (containing oxidised nitrogen) eroding less stable, defect regions of crystal, and advancing inwards along coalescing and diverging pathways, thereby forming nuclei with approximately hemispherical boundaries. An unusual, probably unique, $n+g$ thermal decomposition! This identification of chemical controls for the low-temperature reaction followed decades of kinetic studies (including the reviewer's own Ph.D. thesis, 1958!) which provided no adequate explanation for this exceptional behaviour. Consistent with this interpretation of $\mathrm{NH}_{4} \mathrm{ClO}_{4}$ behaviour, we point out that other $n+g$ reactions, occurring within pore-like structures, are known, e.g. the reaction of chlorine with potassium bromide [88].

Comment We hope these examples collectively and conclusively demonstrate that complementary studies, observational (microscopy) and chemical analyses (qualitative complemented by quantitative), provide essential supports for kinetic studies to elucidate thermal reaction mechanisms and controls for ('initially', i.e. originally!) cold solid reactants.

\section{Discussion}

The idiosyncratic history recounted above is exceptional and, thankfully, is atypical of science and scientists generally. This story merits wider attention as exemplifying a chemical topic, Thermoanalytical Studies, TAS, that spiralled, completely out of control, in ways that eventually resulted in, or at least contributed to, significant modification of the subject area from which it originally sprang! I believe that this, ultimately 'sidelined' topic, arose as a direct consequence of the wide, uncritical use of automated instruments, accepted as being capable of both recording and 'interpreting' kinetic data. My motivation for undertaking this review is to bring this cautionary tale to the attention of main-stream chemists as an example of the consequences of a highly introverted and uncritical approach by a large group of scientists. 
This ability to delegate the 'research' to an instrument, as in 'Thermoanalytical Studies', TAS, was widely recognised and eagerly seized upon by a large group of scientists, as an easy, cheap and quick way to 'score' publications. Despite the transfer, to a inanimate machine, of much of the research effort, these 'researchers' apparently still found it unnecessary to complement or confirm their (so-called) reaction mechanisms with observations, such as microscopy (melting, $n+g$ behaviour) and product analyses (to identify and quantify intermediates). The result was a flood of reports of the thermal decompositions of innumerable and diverse reactants containing few, often no, insights into the chemistry of any of the reactions 'researched'. Consequently, no (scientific) trends of systematic ordering were ever identified within the wide range of reactions studied. Specialist journals appeared, catering for this subject, which effectively sidelined, these publications, disconnecting the topic from main-stream chemistry. Few, if any, critical reviews of this extensive 'literature' ever appeared, attributable to the lack of chemical value or significance in its overall content. Perhaps scientists generally can learn lessons from this prolonged, and hopefully rare, abnormal scientific aberration.

A significant feature of Thermoanalytical Studies, TAS, has been that their publications appeared only in journals specialising in these topics. This has shielded such work from criticisms that could, and should, have come from well-informed referees acting for main-stream, more general, chemical publications. Seemingly 'TAS' researchers have worked to their own set of rules, a conclusion supported by the fact that criticisms of these 'rules', levelled by this author and others [18-28], have been repeatedly ignored. A survey of more recent publications that include citations [47-64] of these critical articles shows that little, usually no, notice has been taken, nor have any 'answers' been attempted. The same ignorant, uncouth attitude has applied to the novel L'vov thermochemical CDV approach to solid-state decompositions [29, 30]. No systematic chemical correlations have yet been found in Thermoanalytical Studies, TAS, yet thermoanalysts still choose to ignore this alternative theory by neither challenging it nor reporting tests of its applicability.

Recently, the number of Thermoanalytical Studies, TAS, publications appearing has markedly declined, perhaps attributable to retirements, or demises [31, 32], of the subject's most prolific protagonists. It appears, therefore, that this subject area has reached, or is about to reach, its natural, but overdue, termination. Though, as a minority speciality, cosily hidden in its cul-de-sac, away from other branches of chemistry, its contributions to the subject will not be missed. This long literature will languish, left lonely, lost in libraries.

A feature of L'vov CDV theory, still probably(?) capable of further development, is its applicability to heterogeneous catalytic reactions $[65,66]$, oxidations of $\mathrm{H}_{2}$ and of $\mathrm{CO}$ on $\mathrm{Pt}$ (also $\mathrm{NiO}$ reduction by $\mathrm{H}_{2}$ [67]). This theory was not available to the heterogeneous catalytic reaction studies on extended metallic surfaces during earlier investigations of the $\mathrm{L}-\mathrm{H}$ and $\mathrm{E}-\mathrm{R}$ reaction mechanisms. It is now possible that interest in the chemistry of these systems might be revived, using thermochemical interpretations based on CDV theory [3].

The potential value of such chemical insights is, however, particularly difficult to assess because our recent literature searches have revealed a trend for heterogeneous catalytic studies to move away from reactions on extended, singlemetal surfaces. Currently, interest appears to favour more complicated and highly dispersed catalyst mixtures. Many include nano-sized particles, with two or more components, such as diverse metal and/or oxide (etc.) combinations. These are often dispersed on high-area supports (zeolites, clays, metal-organic frameworks, etc.) many of which also include additional participating functional, active groups, e.g. acidic sites. It follows that the homogeneous-heterogeneous catalysis distinction is no longer clear-cut, with interest in complicated mixtures of active catalysts evidently growing. Use of un-, or incompletely, characterised severalconstituent reactant mixtures considerably increases the difficulties of kinetic data interpretation. Consequently, much recent research tends to be less amenable to mechanistic studies. Indeed, my survey of recent publications suggests that rate/kinetic studies, apart from comparative measurements of overall activity, are currently of less interest than formerly.

The present situation and possible ways forward From the above history, it seems that recent progress of solidstate thermal chemistry has been appreciably reduced. This is, therefore, an opportune time to review what has already been achieved and what can be built on the foundations. The subject can be regarded as composed of three distinct 'strands', meriting individual consideration.

Thermoanalytical Studies, TAS As shown above, these minimalistic kinetic measurements provide virtually no insights into the chemistries of the numerous reactions 'studied'. Consequently, I cannot recommend this approach as warranting further consideration or even use as a literature resource.

Studies of the thermal chemistries of solids The systems cited above, exemplified by some from the reviewer's laboratory, characterise a few relatively simple reactions that occur on heating initially(!) solid(?) reactants. Studies of further sets of diverse and novel reactions, selected by imaginative researchers, are potentially capable of identifying other systematic, ordered behaviour patterns, thereby extending the scope of solid-state chemistry.

Solid-state chemistry This 'strand', in my view, must have been diminished by all those solid-state chemists who chose to contribute to the, ultimately unproductive, 'Bandwagon': Thermoanalytical Studies, TAS. Nevertheless, 
solid-state thermal chemistry still remains a topic of considerable potential interest and value, both for fundamental science and for commercial and economic applications. Two main reasons motivated the present review. First, advances in instrumentation and of theory, during the decades since the early ground work [4-9], mean that observations of types undreamt of then may now enable novel insights to be obtained into the changes participating in and contributing to these reactions, such as $n+g$, e.g.[72]. A new generation of scientists now has exciting opportunities to formulate worthwhile novel research programmes.

The second important advance is the recognition that the Arrhenius (homogeneous) model is inapplicable to reactions involving solids. In its place, L'vov's thermochemical CDV [3] introduces a completely new approach to elucidating reaction controls and mechanisms for solid-state thermal decompositions. At last, a theory capable of bringing systematic/scientific order into the topic has become available. With this new theory and fewer researchers currently active in this field of thermal solid-state chemistry, notably including heterogeneous catalysis, the time is now ripe for addressing the challenges of imaginatively developing the existing situation with a view to realising its full potential. We hope, therefore, that the situation revealed here will motivate researchers with receptive and enquiring minds, unprejudiced by or unaware of past errors, to exploit these recent advances of theory and of equipment to investigate the kinetics and chemistry of thermal reactions of solids. One starting place would be critical investigations of all aspects of the strengths and weaknesses of the L'vov CDV theory [3].

Heterogeneous catalytic reactions This review also advocates further studies of heterogeneous catalytic reactions to explore possible further applications of the CDV model. Whether this can yield insights into the more complex catalytic processes currently of interest seems doubtful, though perhaps meriting some preliminary exploratory studies.

Mechanochemistry These are chemical transformations promoted by mechanical energy applied to stress solid reactants through friction, shear and/or compressive forces. One apparatus used is the ball-mill, wherein agitated metal spheres impact and thereby grind reactant(s) crystallites, reducing particle sizes and increasing contact areas. However, unlike temperature changes, which distribute energy equally throughout all reactants present, mechanical energy is ever-changing and unevenly apportioned within each reactant particle. An informative introductory article is [89]. The history and applications of mechanochemistry have been reviewed [90-92]. Particularly promising features of this ('Green Chemistry' [93]) method of promoting chemical changes include the absence, or much reduced amounts, of solvents and the ability to obtain commercially valuable products (e.g. sugars, aromatic compounds, etc.) from biomass sources.

Mechanochemistry is mentioned here as a possible route towards gaining insights into mechanisms and/or reactivity controls for reactions involving solids. Examples include crystallite abrasion, equivalent to 'very gentle' mechanochemistry, already known to promote onset the of $n+g$ reactions. Also, the abilities of perovskites to exchange cations offer one experimental approach to investigating the mechanisms of solid-solid reactions. Perovskite chemistry is particularly versatile as shown in the review: 'Perovskites, not just a PV face' [94]. This lists the 'Many Faces of Perovskites', including the use of solids having this crystal structure in batteries, magnets, gamma-ray detectors, superconductors, lasers and ferroelectric materials, certainly an area in which investment of effort in elucidating solid-state thermal reaction mechanisms is likely to yield dividends. This could also contribute to renewing and encouraging wider interests in solid-state chemistry.

Personal comment My motivation for this promotion of solid-state thermal chemistry is because my introduction to research was in this area. I then found the subject stimulating, challenging and now, 65 years later, believe that I may be one of the oldest 'retired(?)' survivors still taking a positive interest the topic. I am convinced that the early promises offered by the subject have not yet been fulfilled, at least in part because the (unproductive) Thermoanalytical Studies, TAS, intervened by slowing its advance. This surge of lowvalue publications must have had a deleterious influence on the progress of solid-state chemistry, an integral component of main-stream chemistry.

Fortuitously, this is a particularly opportune time, following appearance [3] of the novel CDV approach offering chemical insights not available during the earlier work, then unquestioningly maintaining incorrect usage of the Arrhenius (homogeneous) reaction model. Recent appearance of this fundamentally different, but physical chemical approach to kinetic data interpretation could now have, currently unforeseen, wider theoretical implications for chemical science and, in particular, kinetic data interpretation. Thus, the latent, early promises of solid-state chemistry may now become realised. Topics meriting attention! Unfortunately, this long-'retired' observer, lacking laboratory facilities, can do no more than recommend the topic as an exceptionally promising Scientific Topic to a Rising Generation of Scientists, Chemists and/or Physicists, seeking Worthwhile Challenges.

Acknowledgements The reviewer would like to acknowledge, with sincere thanks, the initiative that yielded the review of recent literature: section 'Survey of contents of articles [47-64]' above. This arose in discussions opened by Professor Steven H Strauss, Professor of Chemistry, Colorado State University, Fort Collins, CO 80523, USA. His initial, unexpected letter agreed with, and supported, my earlier publications 
[18-28] criticising the thermochemical literature and the failure of the authors concerned to notice or to respond to the problems identified. With 'Professor Strauss' help, support and advice, I reviewed those literature papers which had citied my publications, but who had ignored their contents. His generous input is acknowledged and much appreciated. I also thank the helpful, but anonymous, reviewer whose generous and thoughtful advice I have gladly taken, believing that this welcome input has materially improved both chemical content and presentation. I most sincerely thank him/her.

Open Access This article is licensed under a Creative Commons Attribution 4.0 International License, which permits use, sharing, adaptation, distribution and reproduction in any medium or format, as long as you give appropriate credit to the original author(s) and the source, provide a link to the Creative Commons licence, and indicate if changes were made. The images or other third party material in this article are included in the article's Creative Commons licence, unless indicated otherwise in a credit line to the material. If material is not included in the article's Creative Commons licence and your intended use is not permitted by statutory regulation or exceeds the permitted use, you will need to obtain permission directly from the copyright holder. To view a copy of this licence, visit http://creativecommons.org/licenses/by/4.0/.

\section{References}

1. Brown ME. Introduction to thermal analysis. 2nd ed. Kluwer: The Netherlands; 2001.

2. Gainsford S, Kett V, Haines P. Principles of thermal analysis and calorimetry. 2nd ed. Chemical Society: London; 2016.

3. L'vov BV. Thermal decompositions of solids and melts: New thermochemical approach to mechanism, kinetics and methodology. Budapest: Springer; 2007.

4. Garner WE, editor. Chemistry of the solid state. London: Butterworth; 1955.

5. Garner WE, editor. Chemistry of the solid state. Chaps. 8 and 9. London: Butterworth; 1955.

6. Jacobs PWM, Tompkins FC. In Chemistry of the solid state, Garner WE, editor. Chaps. 8 and 9. London: Butterworth; 1955.

7. Brown ME, Dollimore D, Galwey AK. Comprehensive chemical kinetics: Reactions in the Solid State, vol. 22. Amsterdam: Elsevier; 1980.

8. Galwey AK, Brown ME. Thermal decomposition of ionic solids. Amsterdam: Elsevier; 1999.

9. Galwey AK, Brown ME. An appreciation of the chemical approach of V. V. Boldyrev to the study of the decomposition of solids. J Thermal Anal Calorim I. 2007;90:9-22.

10. Boldyrev VV, Bulens M, Delmon B. Studies in surface science and catalysis: The control of reactivity of solids, vol. 2. Amsterdam: Elsevier; 1979.

11. Boldyrev VV. Topochemistry of the thermal decomposition of solid substances. Russ Chem Rev. 1973;42:515-28.

12. Boldyrev VV. Thermal decomposition of silver oxalate. Thermochim Acta. 2002;388:63-90.

13. Boldyrev VV. Thermal decomposition of ammonium perchlorate. Thermochim Acta. 2006;443:12-36.

14. Matvienko AA, Maslennikov DV, Zakharov BA, Sidelnikov AA, Chishik SA, Boldyreva EV. Structural aspects of displacive transformations: What can optical microscopy contribute? Dehydration of $\mathrm{Sm}_{2}\left(\mathrm{C}_{2} \mathrm{O}_{4}\right)_{3} \cdot 10 \mathrm{H}_{2} \mathrm{O}$ as a case study. J Appl Cryst. 2017;4(5):588-97.

15. Gribov PA, Matvienko AA, Zakharov BA, Chishik SA, Sidelnikov AA. The study of structural and morphological changes during thermal decomposition of $\mathrm{Y}_{2}\left(\mathrm{C}_{2} \mathrm{O}_{4}\right)_{3} \cdot 10 \mathrm{H}_{2} \mathrm{O}$. Mater Today Proc. 2017;4(11):11470-5.

16. Chishik SA, Matvienko AA, Sidelnikov AA. Spatially-ordered nano-sized crystallites formed by dehydration-induced single crystal cracking of $\mathrm{CuCl}_{2} \cdot 2 \mathrm{H}_{2} \mathrm{O}$. Cryst Eng Commun. 2018;20(39):6005-177.

17. Maslennikov DV, Matvienko AA, Chishik SA, Sidelnikov AA Synthesis and structural characterisation of ceria nanoparticle agglomerates with shape inherited from an oxalate precursor. Ceram Intern. 2019;45:4137-41.

18. Galwey AK. Crystal chemistry and molecular mechanisms in molten magmas: The significance of fusion in reactions of solids. Thermochim Acta. 1995;269-270:621-30.

19. Galwey AK, Brown ME. Arrhenius parameters and compensation behaviour in solid state decompositions. Thermochim Acta. 1997;300:107-15.

20. Galwey AK, Brown ME. Thermal decompositions of solids: Stagnation or progress? J Therm Anal Calorim. 2000;60:863-77.

21. Galwey AK. What is meant by the term "variable activation energy' when applied in the kinetic analyses of solid state decompositions (crystolysis reactions)? Thermochim Acta. 2003;397:249-68.

22. Galwey AK. Eradicating erroneous Arrhenius arithmetic. Thermochim Acta. 2003;399:1-29.

23. Galwey AK. Perennial problems and promising prospects in the kinetic analysis of non-isothermal rate data. Thermochim Acta. 2003;407:93-103.

24. Galwey AK. Is the science of thermal analysis kinetics based on solid foundations? A literature appraisal. Thermochim Acta. 2004;413:139-83.

25. Galwey AK. What theoretical and/or chemical significance is to be attached to the magnitude of an activation energy determined for a solid state reaction? J Therm Anal Calorim. 2006;86:267-86.

26. Galwey AK. Melting and thermal decompositions of solids. An appraisal and mechanistic interpretation of thermal processes in crystals. J Therm Anal Calorim. 2007;87:601-15.

27. Galwey AK. Theory of solid-state thermal decomposition reactions. Scientific stagnation or chemical catastrophe? An alternative approach appraised and advocated. J Therm Anal Calorim. 2012;109:1625-35.

28. Galwey AK. Solid state reaction kinetics, mechanisms and catalysis: a retrospective rational review. React Kinet Mech Catal. 2015;114:1-29. https://doi.org/10.1007/s11144-014-0770-7.

29. L'vov BV. Impact of gaseous environment on kinetics of solidstate decompositions. J Therm Anal Calorim. 2010;100:967-74.

30. L'vov BV. Ups and downs in the theory of decompositions of solids for 130 years. J Therm Anal Calorim. 2017;128:593-600.

31. Harari YN, Deus H. A brief history of tomorrow. London: Penguin; 2017. p. 30.

32. Azoulzy P, Fons-Rosen C, Graff-Zivin JS. Does science advance one funeral at a time? Am Econ Rev. 2019;109:2889-920.

33. Becher JJ, Stahl GE. Formulated 1667. See 'Phlogiston Theory' Wikipedia, on the world-wide-web. Accessed 10 Mar 2020.

34. Carr NJ, Galwey AK. Decomposition reactions of solids (an experiment in reviewing). Thermochim Acta. 1984;79:323-70.

35. Garn PD. The kinetic compensation effect. J Therm Anal. 1976;10:99-102.

36. Garn PD. Kinetic parameters. J Therm Anal. 1978;13:581-93.

37. Garn PD. Temperature coefficient of reaction. Thermochim Acta. 1979;28:185-7.

38. Galwey AK, Craig DQM. Thermogravimetric analysis: Basic principles. In: Craig DQM, Reading M, editors. Thermal analysis of pharmaceuticals, Chapter 5. Boca Raton: Taylor and Francis; 2017. p. 139-191. 
39. Galwey AK, Craig DQM. Thermogravimetric analysis: Pharmaceutical applications. In: Craig DQM, Reading M, editors. Thermal analysis of pharmaceuticals. Boca Raton: Taylor and Francis; 2007. p. 193-21.

40. Johnson M. The importance of solid form science in modern drug development. Chem World R Soc Chem. 2019;16:54.

41. Brown ME, Maciejewski M, Vyazovkin S, et al. Computational aspects of kinetic analysis: Part A: The ICTAC Kinetics Projectdata, methods and results. Thermochim Acta. 2000;355:15-143.

42. L'vov BV, Galwey AK. Towards a general theory of heterogeneous reactions: Thermochemical approach. J Therm Anal Calorim. 2013;113:561-8.

43. L'vov BV, Galwey AK. Interpretation of the kinetic compensation effect in heterogeneous reactions: Thermochemical approach. Int Rev Phys Chem. 2013;32:515-57. https://doi.org/10.1080/01442 35X.2013.802109.

44. Galwey AK. Magnitudes of Arrhenius parameters for thermal decompositions of solids. Thermochim Acta. 1994;242:259-64.

45. Galwey AK. Compensation effect in heterogeneous catalysis. Adv Catal. 1977;26:247-32222.

46. Sestak J. Is the original Kissinger equation obsolete today: not obsolete the entire non-isothermal kinetics? J Therm Anal Calorim. 2014;117:3-7.

47. Jankovic B. Kinetic modelling of native Cassava starch thermooxidatative degradation using Weibull and Weibull-derived models. Biopolymers. 2014;101:41-57.

48. Kolezynski A, Handke B, Drozdz-Clesla E. Crystal structure, electronic structure, bonding properties of anhydrous nickel oxalate. J Therm Anal Calorim. 2013;113:319-28.

49. Peng Y, Wang F, Wang Z, Alsayed AM, Zhang Z, Yodh AG, Han Y. Two step nucleation mechanism in solid-solid transitions. Nat Mater. 2015;14:101-8.

50. Cui H-W, Jiu J-T, Sughara T, Nagao S, Suganuma K, Uchida H, Schroder KA. Using the Friedman method to study the thermal degradation kinetics of photonically cured electrically conductive adhesives. J Therm Anal Calorim. 2015;119:425-33.

51. Khachani M, El Hamidi A, Kacimi M, Halim M, Arsalane S. Kinetic approach to multi-step thermal decomposition processes of iron(III) phosphate dihydrate $\mathrm{FePO}_{4} \cdot 2 \mathrm{H}_{2} \mathrm{O}$. Thermochim Acta. 2015;610:29-36.

52. Wang S, Ru B, Lin H, Dai G, Wang Y, Luo Z. Kinetic study on biomass components: a critical review. Curr Org Chem. 2016;20:2489-513.

53. Minawoski A, Urbanczyk W. Thermal dissociation in terms of the second law of chemical thermodynamics. J Therm Anal Calorim. 2016;126:862-70.

54. Lente G. Editor React Kinet Mech Catal. 2016;119:3-4

55. Sronsci C, Danvirutai C, Noisong P. Double function method for the confirmation of the reaction mechanism of $\mathrm{LiCoPO}_{4}$ nanoparticle formation, reliable activation energy and related thermodynamic functions. React Kinet Mech Catal. 2017;121:555-77.

56. Sharma HN, Sangalang EA, Cheng KS, Calms G, McClean W, Maxwell RS, Long ND. Volatility of the catalytic hydrogenation products of 1,4 bis(bhenylethynyl)benzene. J Chem Phys. 2017;147:194701

57. Tian H, Cai L, Jiang T, Zhang H, Li X, Dong M, Lu J. Study of kinetic characteristics of limestone decomposition under different atmospheres and heating conditions. J Therm Anal Calorim. 2017;130:2351-8.

58. John J, Devi RS, Balachandran S, Babu KVD. Synthesis, spectral characterization and thermal analysis of rubrocurcumin and its analogues. J Therm Anal Calorim. 2017;130:2301-14.

59. Mohammad KA, Abd Rahima S, Abu Bakar MR. Kinetics and nucleation mechanism of carbamazepine-saccharin co-crystals in ethanol solution. J Therm Anal Calorim. 2017;130:1663-9.
60. Wang P-C, Xie Q, Xu Y-G, Wang J-Q, Lin Q-B, Lu M. A kinetic investigation of thermal decomposition of 1,1'-dihydroxy-5,5'bitetrazole-metal salts. J Therm Anal Calorim. 2017;130:1213-20.

61. Begovic NN, Vasic MM, Blagojevic VA, Filipovic NR, Marinkovic $\mathrm{AD}$, Malesevic A, Minic DM. Synthesis and thermal stability of cis-dichlorool[(E)-ethyo-2-(2-((8-hydroxyquinolin-2-il)methylene)hidrazinyl) acetate- $\mathrm{K}^{2} N$ ]-palladium complex. J Therm Anal Calorim. 2017;130:701-11.

62. Parvanova V. Synthesis and thermal decomposition of neodymium(III) peroxotitanate to $\mathrm{Nd}_{2} \mathrm{TiO}_{5}$. J Therm Anal Calorim. 2017;130:695-700.

63. Juibari NM, Eslami A. Green synthesis of $\mathrm{ZnCo}_{2} \mathrm{O}_{4}$ nanoparticles by Aloe albiflora extract and its application as catalyst on thermal decomposition of ammonium perchlorate. J Therm Anal Calorim. 2017; 130:1327-33.

64. Pinto BV, Ferreira APG, Cavalheiro ETG. A mechanism proposal for fluoxethine thermal decomposition. J Therm Anal Calorim. 2017;130:1553-9.

65. L'vov BV, Galwey AK. Catalytic oxidation of hydrogen on platinum: Thermochemical Approach. J Therm Anal Calorim. 2013;112:815-22.

66. L'vov BV, Galwey AK. Catalytic oxidation of CO on platinum: Thermochemical approach. J Therm Anal Calorim. 2013;111:145-54.

67. L'vov BV, Galwey AK. The mechanism and kinetics of NiO reduction by hydrogen: Thermochemical approach. J Therm Anal Calorim. 2012;110:601-10.

68. Atkins P, de Paula J. Atkins' physical chemistry. 8th ed. Oxford: Oxford University Press; 2006. p. 927-932.

69. Atkins P, de Paula J, Friedman R. Quanta, matter and change. Oxford: Oxford University Press; 2009. p. 711.

70. Galwey AK, Gray P, Griffiths JF, Hasko SM. Surface retexturing of platinum wires during the catalytic oxidation of $\mathrm{CO}$. Nature. 1985;313:668-71.

71. Scott K, Griffiths JF, Galwey AK. Restructuring of catalyst surfaces during oscillatory reactions. In: Gray P, Nicolis G, Baras F, et al., editors. Spatial in homogeneities and transient behaviour in chemical kinetics. Manchester: Manchester University Press; 1990. p. 579-592.

72. Zhou J, et al. Observing crystal nucleation in four dimensions using atomic electron tomography. Nature. 2019;570:500-3.

73. Brown ME, Galwey AK, Mohamed MA, Tanaka H. A mechanism for the thermal decomposition of potassium permanganate crystals based on nucleation and growth. Thermochim Acta. 1994;235:255-70.

74. Carr NJ, Galwey AK. The kinetics and mechanism of the thermal decomposition of copper(II) malonate. Proc R Soc Lond A. 1986;404:101-26.

75. Galwey AK, Reed R, Guarini GGT. Observations on internal structures of chrome alum dehydration nuclei. Nature. 1980;283:52-4.

76. Galwey AK, Spinicci R, Guarini GGT. Nucleation and growth processes occurring during the dehydration of certain alums: The generation, the development and the function of the reaction interface. Proc R Soc Lond A. 1981;378:477-505.

77. Galwey AK, Guarini GGT. A kinetic study of the dehydrations of the alums $\mathrm{KCr}\left(\mathrm{SO}_{4}\right)_{2} \cdot 12 \mathrm{H}_{2} \mathrm{O}$ and $\mathrm{KAl}\left(\mathrm{SO}_{4}\right)_{2} \cdot 12 \cdot \mathrm{H}_{2} \mathrm{O}$. Proc R Soc Lond A. 1993;441:319-29.

78. Galwey AK, Jamieson DM, Brown ME. Thermal decomposition of three crystalline modifications of anhydrous copper(II) formate. J Phys Chem. 1974;78:2664-700.

79. Carr NJ, Galwey AK. Thermal decomposition reactions of copper maleate and of copper fumarate. J Chem Soc Faraday Trans. 1988;84:1357-73. 
80. Jamieson DM, Galwey AK. Mobility of copper metal during heterogeneous catalytic decomposition of formic acid. J Catal. 1974;34:156-8.

81. Jones KA, Acheson RJ, Wheeler BR, Galwey AK. Thermal decomposition of nickel malonate. Trans Faraday Soc. 1968;64:1887-97.

82. McGinn MJ, Wheeler BR, Galwey AK. Thermal decomposition of nickel fumarate. Trans Faraday Soc. 1970;66:1809-16.

83. McGinn MJ, Wheeler BR, Galwey AK. Thermal decomposition of nickel maleate. Trans Faraday Soc. 1971;67:1480-8.

84. Galwey AK, Pöppl L, Sundara R. The mechanistic significance of melt formation during the thermal decomposition of ammonium dichromate. J Chem Soc Faraday Trans. 1983;1(79):2143-51.

85. Galwey AK, Mohamed MA. The formation of $\mathrm{NO}_{2} \mathrm{ClO}_{4}$ as an intermediate during the low temperature thermal decomposition of ammonium perchlorate. J Chem Soc Chem Commun. 1984;18:1197-8.

86. Galwey AK, Mohamed MA. Nitryl perchlorate as the essential intermediate in the thermal decomposition of ammonium perchlorate. Nature. 1984;311:642-5.

87. Galwey AK, Mohamed MA. The low temperature thermal decomposition of ammonium perchlorate: Nitryl perchlorate as the reaction intermediate. Proc R Soc Lond A. 1984;396:425-40.
88. Galwey AK, Pŏppl L. The development and the function of the interface participating in the nucleation and growth reaction between crystalline potassium bromide and chlorine gas. Philos Trans R Soc Lond A. 1984;311:159-83.

89. James S, Friščić T. Mechanochemistry. Chem Soc Rev Lond. 2013;42:7487-740.

90. Luque R. Mechanochemistry. ACS Chem Community: On line blog post: 22nd Feb 2018 (Accessed 25th March 2019)

91. Boldyrev VV. Mechanochemical processes with reaction-induced mechanical activation: Chemo-mechanochemical effect. Russ Chem Bull Int. 2018;67:1-16.

92. Boldyrev VV. Mechanochemistry in Siberia: Herald. Russ Acad Sci. 2018;88:142-50.

93. Seo T, Ishiyama T, Kubota K, Ito H. Solid state Suzuki-Miyara cross-coupling reaction: Olefin accelerated $\mathrm{C}-\mathrm{C}$ coupling using mechanochemistry. Chem Sci. 2019;10:8202-10.

94. Crow JM (2019) Chem World R Soc Chem Lond. pp 22-27, Perovskites, not just a PV face.

Publisher's Note Springer Nature remains neutral with regard to jurisdictional claims in published maps and institutional affiliations. 